\title{
Nucleolar Localization of HIV-1 Rev Is Required, Yet Insufficient for Production of Infectious Viral Particles
}

\author{
Jerlisa Ann C. Arizala, ${ }^{1,2}$ Mayumi Takahashi,,2 John C. Burnett, \\ Dominique L. Ouellet, Haitang Li, and John J. Rossi ${ }^{1,2}$
}

\begin{abstract}
Combination antiretroviral therapy fails in complete suppression of HIV-1 due to drug resistance and persistent latency. Novel therapeutic intervention requires knowledge of intracellular pathways responsible for viral replication, specifically those untargeted by antiretroviral drugs. An understudied phenomenon is the nucleolar localization of Rev phosphoprotein, which completes nucleocytoplasmic transport of unspliced/partially spliced HIV mRNA through multimerization with intronic cis-acting targets-the Rev-response element (RRE). Rev contains a nucleolar localization signal (NoLS) comprising the $\mathrm{COOH}$ terminus of the arginine-rich motif for accumulation within nucleoli-speculated as the interaction ground for Rev with cellular proteins mediating mRNA-independent nuclear export and splicing. Functionality of Rev nucleolar access during HIV-1 production and infection was investigated in the context of deletion and single-point mutations within Rev-NoLS. Mutations induced upon Rev-NoLS are hypothesized to inactivate the HIV-1 infectious cycle. HIV-1 $1_{\mathrm{HXB} 2}$ replication ceased with Rev mutations lacking nucleolar access due to loss or replacement of multiple arginine residues. Rev mutations missing single arginine residues remained strictly nucleolar in pattern and participated in proviral production, however, with reduced efficiency. Viral RNA packaging also decreased in efficiency after expression of nucleolar-localizing mutations. These results were observed during propagation of variant HIV-1 $1_{\text {NL4-3 }}$ containing nucleolar-localizing mutations within the viral backbone (M4, M5, and M6). Lentiviral particles produced with Rev single-point mutations were transducible at extremely low frequency. Similarly, HIV-1 $1_{\text {NL4-3 }}$ Rev-NoLS variants lost infectivity, unlike virulent WT (wild type) HIV-1 $1_{\mathrm{NL} 4-3}$. HIV-1 $1_{\mathrm{NL} 4-3}$ variants were capable of $\mathrm{CD}_{4}^{+}$host entry and reverse transcription as WT HIV-1 $1_{\mathrm{NL} 4-3}$, but lacked ability to complete a full infectious cycle. We currently reveal that viral integration is deregulated in the presence of Rev-NoLS mutations.
\end{abstract}

Keywords: HIV replication, Rev, nucleolus, HIV integration, HIV mRNA splicing, nucleocytoplasmic transport

\section{Introduction}

A $\mathrm{N}$ UNDEREXPLORED AREA in HIV-1 research is the nucleolar pathway viral proteins Tat and Rev participate in during viral proliferation. Unlike Tat, which accumulates in the nucleus and nucleolus, Rev has mainly nucleolar subcellular localization. Upon viral infection, HIV genomic reverse transcription and proviral integration into host chromosome leads to cellular Pol II-dependent early expression of env-derived proteins Tat, Rev, and Nef. Tat facilitates transcription and expression of viral genes after association with a transactivation response element (TAR) found within $5^{\prime} L T R$ of HIV transcripts. ${ }^{1-4}$ Rev achieves nucleocytoplasmic transport of HIV mRNAs through recognition of the Rev-response element $(\mathrm{RRE})^{4-7}$ " $\mathrm{A}$ ”, conformation within $e n v$.

The "A" conformation involves Rev binding sites IIB and IA that compose the opposite legs of the "A" shape. Arginine-rich motif (ARM) of Rev monomer binds IIB with high affinity, ${ }^{9-11}$ exposing a dimerization interface for a second Rev monomer to bind. ${ }^{12}$ Rev monomers achieve

\footnotetext{
${ }^{1}$ Department of Molecular and Cellular Biology, Beckman Research Institute at the City of Hope, Duarte, California.

${ }^{2}$ Irell \& Manella Graduate School of Biological Sciences, Duarte, California.

(C) Jerlisa Ann C. Arizala et al. 2018; Published by Mary Ann Liebert, Inc. This Open Access article is distributed under the terms of the Creative Commons Attribution Noncommercial License (http://creativecommons.org/licenses/by-nc/4.0/) which permits any noncommercial use, distribution, and reproduction in any medium, provided the original author(s) and the source are cited.
} 
multimerization throughout the RRE, ${ }^{13,14}$ mainly within the nucleolus. ${ }^{15}$ Nuclear export of Rev-RRE RNP (ribonucleoprotein) complex occurs through the Rev nuclear export signal (NES) interaction with chromosomal region maintenance 1 (CRM1) ${ }^{16,17}$ and GTP-bound Ran, ${ }^{18}$ leading to accumulation of intron-containing unspliced $(9 \mathrm{~kb}$ full-length genome containing gag/pol) and partially spliced $(4 \mathrm{~kb}$ fragment containing vif, $v p r, v p u$, and $e n v$ ) HIV transcripts in cytoplasm for viral protein expression and viral particle assembly. ${ }^{19,20}$

HIV-1 transcripts were previously identified in the nucleolus of infected peripheral blood mononuclear cells (PBMC) during electron microscopy and in situ hybridization with probes complementary to gag, env, and nef. ${ }^{21}$ A nucleolar therapeutic model was hence developed against HIV-1 production, utilizing a hammerhead ribozyme placed within U16 small nucleolar RNA platform (U16Rz) and targeted against conserved motifs within HIV-1 5'LTR. U16Rz was expressed in HeLa T4, where nucleolar specificity was observed. Upon HIV challenge, nucleolar U16Rz strongly suppressed HIV-1 production, ${ }^{22}$ selectively cleaving unspliced and partially spliced transcripts that traversed through the nucleolus to the sequestered ribozyme. Similarly, modified U16Rz targeting both U5 and gag ( $\mathrm{RzC} 36)$ significantly reduced viral production in CEM during HIV challenge. ${ }^{23}$

The potent catalytic activity of nucleolar-specific U16Rz against HIV RRE-containing transcripts suggests an HIV-1 nucleolar pathway facilitated through Rev nucleocytoplasmic activity.

The dynamic and multifunctional nucleolar proteome enables ribosome subunit biosynthesis, cell cycle control, apoptosis, DNA replication/repair, RNP biogenesis, and stress response within subnucleolar compartments-fibrillar centers, dense fibrillar components (DFC), and outermost granular components (GC). ${ }^{24,25}$

Viral pathogenesis induces cellular stress, leading to transformation in nucleolar proteomic morphology as nucleolar-accessible viral proteins recruit replication factors. $^{26,27}$ Similar to HIV-1 Rev, the following single-strand RNA viruses express nucleolar RNA binding proteins of diverse functionality: severe acute respiratory coronavirus nucleocapsid $(\mathrm{N})$ harbors an NES predicted in nucleocytoplasmic shuttling activity ${ }^{28}$; dengue virus core protein facilitates encapsidation and potentially modulates transcription $^{29}$; and the Semliki Forest virus nonstructural protein $(\mathrm{nsP} 2)$ regulates viral mRNA synthesis. ${ }^{30}$

Although nucleolar trafficking is prevalent in many viral infectious models, the purpose of this localization pattern is unknown. In the case of HIV-1, the nucleolus may serve as the interaction ground for Rev with cellular proteins that facilitate rapid mRNA nuclear export and protect HIV mRNA from spliceosomal complexes. ${ }^{31}$

Rev subnucleolar localization within DFC and $\mathrm{GC}^{32} \mathrm{oc}-$ curs through a nucleolar localization signal (NoLS) ${ }^{45}$ WRERQRQ ${ }^{51}$, directly downstream of the nuclear localization sequence (NLS) ${ }^{34}$ TRQARRNRRRR ${ }^{44}$ within Rev ARM. ${ }^{33,34}$ Rev nucleolar localization was originally demonstrated to occur through amino acids 40-45 (NRRRRW) within the Rev NLS. ${ }^{35}$ Studies by Cochrane et al. later identified amino acid residues within 35-50 of the Rev ARM as vital for nucleolar accumulation. ${ }^{34}$ Using site-directed mutagenesis to alter amino acids surrounding the Rev NLS and indirect immunofluorescence, Rev localization of mutations lacking amino acids 48-51 (RQRQ) maintained nucleolar accumulation in the absence of HIV production.

However, when deletions were expanded to residues WRE, resulting in complete elimination of WRERQRQ (amino acids 45-51), nuclear accumulation was observed. ${ }^{34}$ Although a potential Rev-NoLS was identified at amino acids 45-51 downstream of the NLS, functionality of Rev nucleolar mutations was not investigated in the context of HIV-1 production and infection.

To characterize Rev nucleolar function, HIV-1 production and infection were examined in the presence of Rev nucleolar mutations. We currently reveal that Rev nucleolar access is necessary for the completion of the HIV-1 infectious cycle. Nucleolar activity allows efficient HIV-1 mRNA splicing and nucleocytoplasmic transport. In the background of Rev nucleolar mutations, the frequency of viral integration increases dramatically in comparison to WT (wild type) HIV-1. Extreme integration frequencies result in cell death and the arrest of the HIV-1 infectious cycle. We further demonstrate the loss of Rev interaction with B23 as a result of nucleolar mutations, and discuss the involvement of B23 in other viral infectious models requiring nucleolar access for infectivity.

\section{Materials and Methods}

\section{Cell culture}

HeLa cells containing stably integrated copies of a Revdeficient HIV-1 $1_{\mathrm{HXB} 2}$ molecular clone $(\mathrm{HLfB})$ were obtained from the NIH AIDS Research and Reference Reagent Program (\#1300). HLfB, HeLa (\#CCL-2; American Type Culture Collection), $\mathrm{CD}^{+}$HeLa (T4), human embryonic kidney $293 \mathrm{~T}$ (HEK293T), and human fibrosarcoma (HT1080) were cultured in Dulbecco's modified Eagle's medium (DMEM) supplemented with $10 \%$ fetal bovine serum (FBS), 2 mM L-glutamine, and $1 \mathrm{mM}$ sodium pyruvate at $37^{\circ} \mathrm{C}$ within a humidified chamber with $5 \% \mathrm{CO}_{2}$. Jurkat JLTRG-R5 reporter cells (NIH AIDS Research and Reference Reagent Program \#11586) expressing CD4 receptor and CCR5/CXCR4 co-receptors and T cell lymphoblast (CEM) were maintained in RPMI-1640 supplemented with $10 \%$ FBS, $2 \mathrm{mM}$ L-glutamine, $1 \mathrm{mM}$ sodium pyruvate, $100 \mathrm{U} / \mathrm{ml}$ penicillin, and $100 \mu \mathrm{g} / \mathrm{ml}$ streptomycin.

\section{Site-directed mutagenesis of Rev-NoLS}

$C M V$-driven Rev-EGFP fusion within pcDNA platform ${ }^{36}$ was a template for QuickChange II site-directed mutagenesis (Agilent Technologies). Primer sequences were designed according to mutations of interest within Rev-NoLS (Table 1). Primer sequences in Table 1 were also used to generate 3'Flag-tagged Rev mutations within pcDNA3.1. Single-point mutations and deletions were confirmed through DNA sequencing.

\section{Site-directed mutagenesis of pNL4-3 Rev-NoLS}

The Rev-NoLS fragment ( $\sim 1,200 \mathrm{bp}$ ) was excised from pNL4-3 (NIH AIDS Research and Reference Reagent Program \#114) using NheI and BamHI restriction digests and ligated into pcDNA3.1. The restriction fragment was a template for site-directed mutagenesis using primer sets (Table 2) designed to establish mutations of Rev-NoLS M4, M5, M6, 
Table 1. Mutagenic Rev-Nols Primers Corresponding to Rev Template

\begin{tabular}{|c|c|c|}
\hline Mutation & Mutagenic primer set $\left(5^{\prime}-3^{\prime}\right)$ & Template \\
\hline M1- $\Delta 48-51$ & $\begin{array}{l}\text { GAATAGAAGGCGCCGGTGGAGAGAGATCCATTCGATATC/ } \\
\text { GATATCGAATGGATCTCTCTCCACCGGCGCCTTCTATTC }\end{array}$ & Rev \\
\hline M2-R48,50G & $\begin{array}{l}\text { GAGAGAGGGACAGGGACAGATCCATTCGATATCTGAAC/ } \\
\text { GTTCAGATATCGAATGGATCTGTCCCTGTCCCTCTCTC }\end{array}$ & Rev M5 \\
\hline M4-R46G & $\begin{array}{l}\text { GCGCCGGTGGGGAGAGAGACAGAGACAGATCCATTCGATATC/ } \\
\text { GATATCGAATGGATCTGTCTCTGTCTCTCTCCCCACCGGCGC }\end{array}$ & WT Rev \\
\hline M5-R48G & $\begin{array}{l}\text { GTGGAGAGAGGGACAGAGACAGATCCATTCGATATCTGAAC/ } \\
\text { GTTCAGATATCGAATGGATCTGTCTCTGTCCCTCTCTCCAC }\end{array}$ & WT Rev \\
\hline M6-R50G & $\begin{array}{l}\text { GGAGAGAGAGACAGGGACAGATCCATTCGATATCTGAAC/ } \\
\text { GTTCAGATATCGAATGGATCTGTCCCTGTCTCTCTCTCC }\end{array}$ & WT Rev \\
\hline M7- $\Delta 45-51$ & $\begin{array}{l}\text { GAATAGAAGGCGCCGGATCCATTCGATATCTGAAC/ } \\
\text { GTTCAGATATCGAATGGATCCGGCGCCTTCTATTC }\end{array}$ & Rev M1 \\
\hline M8- $\Delta 50-51$ & $\begin{array}{l}\text { GCCGGTGGAGAGAGAGACAGATCCATTCGATATC/ } \\
\text { GATATCGAATGGATCTGTCTCTCTCTCCACCGGC }\end{array}$ & WT Rev \\
\hline M9-R46,48,50G & $\begin{array}{l}\text { GAATAGAAGGCGCCGGTGGGGAGAGGGACAGGGACAGATCCATTC/ } \\
\text { GAATGGATCTGTCCCTGTCCCTCTCCCCACCGGCGCCTTCTATTC }\end{array}$ & Rev M2 \\
\hline
\end{tabular}

WT, wild type.

and M8 specifically. Mutant-positive fragment was excised and reintroduced into the $\mathrm{pNL} 4-3$ backbone.

DNA sequencing was used to confirm the presence of each Rev-NoLS mutation and deletion. WT pNL4-3 contains reintroduced, nonmutated Rev-NoLS restriction fragment, ligated alongside single-point mutant fragments into $\mathrm{pNL4}$-3. Bacterial colony PCR screens using forward primers specific to each Rev-NoLS mutation (Table 3) in combination with Env reverse primer 5'-CGAATAGCTCTA TAAGCTGCTTGTAA-3' were used to amplify the following mutant clones: pNL4-3 M4; pNL4-3 M5; and pNL4-3 M6. DNA sequencing was used to confirm the presence of mutation cDNA fragments within $\mathrm{p} N L 4-3$.

Restriction digest sets- $B b v \mathrm{CI}$ with $A h d \mathrm{I}$ and DraII with Pst I-were used to analyze WT, pNL4-3 M4, and pNL4-3 M8 for chromosomal rearrangement using original $\mathrm{pNLA}-3$ plasmid as a control. Restriction digest sets-BbvCI with $A h d \mathrm{I}$ and DraIII with Pst - were used next to analyze $\mathrm{p} N L 4$ 3 M5 and pNL4-3 M6. All pNL4-3 mutations chosen to propagate viral particles were subjected to a final analysis for chromosomal rearrangement with three restriction digest sets-PstI and DraIII, BbvCI and AhdI, and NdeI and AhdI

TABle 2. PNL4-3 Rev-NoLS MutageniC PRIMERS

\begin{tabular}{|c|c|}
\hline Mutation & Mutagenic primer set $\left(5^{\prime}-3^{\prime}\right)$ \\
\hline \multirow[t]{4}{*}{ M4-R46G } & GAAGAAGGTGGGGAGAGAGACAGAGA \\
\hline & CAGATCCATTCGATTAG/CTAATCGA \\
\hline & ATGGATCTGTCTCTGTCTCTCTCCC \\
\hline & CACCTTCTTC \\
\hline \multirow[t]{4}{*}{ M5-R48G } & GTGGAGAGAGGGACAGAGACAGATCC \\
\hline & ATTCGATTAGTGAAC/GTTCACTAAT \\
\hline & CGAATGGATCTGTCTCTGTCCСTCT \\
\hline & СТССАС \\
\hline \multirow[t]{3}{*}{ M6-R50G } & GGAGAGAGAGACAGGGACAGATCCAT \\
\hline & TCGATTAGTGAAC/GTTCACTAATCG \\
\hline & AATGGATCTGTCCCTGTCTCTCTCTCC \\
\hline \multirow[t]{3}{*}{$M 8-\Delta 50-51$} & GAAGGTGGAGAGAGAGACAGATCC \\
\hline & ATTCGATTAG/CTAATCGAAT \\
\hline & GGATCTGTCTCTCTCTCCACCTTC \\
\hline
\end{tabular}

(Supplementary Fig. S3A-C). Mutant plasmids matching in digestion fragment pattern with WT $\mathrm{pNLA-3}$ were used to propagate $\mathrm{HIV}-1_{\mathrm{NL} 4-3}$ particles.

\section{Confocal microscopy}

HLfB and HeLa $\left(1 \times 10^{5}\right.$ cells $)$ were cultured onto $0.01 \%$ poly-L-lysine-treated 8-chamber CultureSlides (Falcon). Cells were transfected the following day with $0.5 \mu \mathrm{g} \mathrm{Rev-}$ NoLS-EGFP mutations using Lipofectamine 2000 reagent (Invitrogen). Cells were fixed $12 \mathrm{~h}$ later in $4 \%$ paraformaldehyde, permeabilized in $0.1 \%$ Triton X-100, and blocked in $10 \%$ FBS for $1 \mathrm{~h}$ at room temperature. B23 mouse monoclonal $\mathrm{IgG}_{1}$ (\#sc-47725; Santa Cruz Biotechnologies) diluted to $1: 250$ in $10 \%$ FBS was incubated on cells for $1 \mathrm{~h}$.

Cells were washed in triplicate with $1 \times$ phosphate-buffered saline (PBS) and subjected to 1-h incubation in Alexa Fluor 555 goat-anti-mouse $\mathrm{IgG}_{1}$ diluted to $1: 100$. Cells were rinsed and stained with 4',6-diamino-2-phenylindole (DAPI, $1 \mu \mathrm{g}$ / $\mathrm{ml}$; Sigma-Aldrich) for $5 \mathrm{~min}$. Glass cover slips were mounted onto cells using Prolong Gold anti-fade reagent (Invitrogen) and stored at $4^{\circ} \mathrm{C}$ in darkness. Images were taken with a Zeiss Upright LSM510 2-Photon Microscope at $63 \times$ magnification in oil immersion and $1.7 \times$ zoom.

Table 3. List of Forward Primers Used in Mutant pNL4-3 Bacterial Colony Polymerase Chain Reaction Screen

\begin{tabular}{ll}
\hline Mutation & \multicolumn{1}{c}{ Mutagenic primer set $\left(5^{\prime}-3^{\prime}\right)$} \\
\hline M4-R46G & GAAGGAATAGAAGAAGAAGGTGGG \\
M5-R48G & GAATAGAAGAAGAAGGTGGAGAGAGG \\
M6-R50G & GAAGAAGAAGGTGGAGAGAGAGACAGG \\
M8- $450-51$ & GAAGAAGGTGGAGAGAGAGACAGAT \\
\hline
\end{tabular}

Nucleotides bolded in black represent each single-point mutation present within the mutated clone. Nucleotides bolded in gray represent the region located directly downstream of the M8 RQ deletion. List of primer sets used in mutant $\mathrm{pNLA}-3$ bacterial colony PCR screen.

PCR, polymerase chain reaction. 
HIV-1 ${ }_{\text {HXB2 }}$ production

HLfB cells $\left(1 \times 10^{6}\right.$ cells $)$ were grown in six-well tissue culture plates to $50 \%$ confluency and transfected with $5 \mu \mathrm{g}$ of vector plasmid containing Rev-EGFP or Rev-3'Flag (WT and mutations) using the $\mathrm{CaCl}_{2}$ method. Supplemented DMEM $(1 \mathrm{ml})$ was replaced $5 \mathrm{~h}$ later. Viral-containing supernatant was collected $48 \mathrm{~h}$ post-transfection and centrifuged at $1,000 \mathrm{rpm}$ for $5 \mathrm{~min}$ to remove cell debris. Viral supernatant was quantified for p24 capsid protein using HIV-1 p24 ELISA (PerkinElmer Life Sciences, Inc.).

\section{HIV-1 $1_{\text {HХB2 }}$ RNA packaging}

Viral particles generated in the presence of Rev-NoLS mutations were analyzed for packaged RNA using Quantigene 2.0 bDNA detection (Affymetrix-Panomics Solutions), using probe sets specific to highly conserved regions within HIV-1 vif (\#SF-10183-01; Affymetrix, Inc.).

\section{HIV-1 ${ }_{N L 4-3}$ infection}

HIV-1 $1_{\text {NL4-3 }}$ cDNA harboring Rev-NoLS mutations was transfected into HEK293T (50\% confluent) with $\mathrm{CaCl}_{2}(1 \mu \mathrm{g} /$ well) within 12-well culture plates. Viral supernatant was collected $48 \mathrm{~h}$ later, cleared of cell debris, and quantified for p24 production. Viral supernatant normalized to $2 \mathrm{ng}$ p24 was used to infect JLTRG-R5 precultured at $1 \times 10^{6}$ cells per well. HIV-1-exposed cells were washed thrice in $2 \times$ HBSS $24 \mathrm{~h}$ after infection and resupplemented with RPMI media. To assess infectivity of mutant $\mathrm{HIV}-1_{\mathrm{NL} 4-3}$ variants, cells were collected every 5 days, stained with LIVE/DEAD aqua dead cell stain (Life Technologies), fixed in $3.7 \%$ paraformaldehyde, and measured for aqua fluorescence $(405 \mathrm{~nm}$ excitation) with CyAn ADP 9 Color FACS analysis. Live cells were analyzed for HIV-1 infection through EGFP emission (488 $\mathrm{nm}$ excitation).

\section{PCR detection of total HIV and 2-LTR circle DNA}

Supernatant of HIV-1 $1_{\text {NL4-3 }}$-WT and Rev-NoLS mutations - was normalized to $20 \mathrm{ng}$ capsid p24 for infection of JLTRG-R5 populated at $1 \times 10^{6}$ cells per well of 12 -well culture plates. Infected cells were washed through suspension in $2 \times$ HBSS, thrice, $24 \mathrm{~h}$ after viral exposure and replenished with RPMI media. Cells were harvested every 5 days for genomic DNA extraction using QIAamp DNA Mini kit (Qiagen). Amplification of total HIV-1 and 2-LTR circle DNA was achieved using $1 \mu \mathrm{g}$ genomic DNA subjected to PCR primer sets $(0.5 \mu \mathrm{M}$ in final volume $)$ and annealing conditions described. 37

Positive control fragments were derived through PCR amplification of genomic DNA from HIV-infected CEM (total HIV DNA) and infected CEM treated with integrase inhibitor 118-D-24 (2-LTR circle) (NIH AIDS Research and Reference Reagent Program \#9957, $20 \mu \mathrm{m}$ in final volume). Primer sets specific to $\beta$-globin gene-Forward $5^{\prime}$-CCC TTG GAC CCA GAG GTT CT-3' and Reverse 5'-CGA GCA CTT TCT TGC CAT GA-3' - were used as amplification and gel loading controls under identical annealing conditions alongside total HIV-1 and 2-LTR circle primer sets.

\section{Lentiviral transduction}

Using $\mathrm{CaCl}_{2}$, the following $\mathrm{HIV}$-1-based self-inactivating (SIN) vector and lentiviral packaging plasmids were cotransfected into HEK293T at 50\% confluency: $15 \mu \mathrm{g}$ pHIV7/

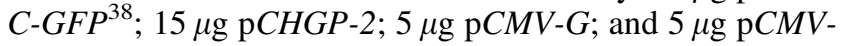
Rev-WT or NoLS-mutation. Lentiviral supernatant was collected and concentrated as previously mentioned. ${ }^{39}$ Five hundred picograms p24 supernatant was used to transduce, through polybrene transduction $(4 \mu \mathrm{l} / \mathrm{ml})$, HT1080 cells grown to $1 \times 10^{5}$ cells per well in 12 -well plates. Transduced cells were collected $48 \mathrm{~h}$ post-transduction, fixed in $3.7 \%$ paraformaldehyde, and EGFP reporter quantified using CyAn ADP 9 Color FACS analysis.

\section{Northern blot analysis of HIV-1 mRNA splicing}

Total RNA from HEK293T transfected with $5 \mu \mathrm{g}$ HIV-1 $\mathrm{p} N L 4-3$ (50\% confluent in $10 \mathrm{~cm}$ culture plates), WT and RevNoLS variants, was collected $48 \mathrm{~h}$ later using RNA STAT-60 (Tel-Test, Inc.) according to the manufacturer's instructions. Forty micrograms total RNA was electrophoresed on $1 \%$ agarose/formaldehyde, ethidium bromide-stained gels, and transferred onto Hybond $-\mathrm{N}$ nucleic acid membrane (GE Healthcare).

RNA membrane was ultraviolet-crosslinked and blocked in $1 \times$ PerfectHyb Plus hybridization buffer (Sigma) for $1 \mathrm{~h}$ at $70^{\circ} \mathrm{C}$. HIV RNA was detected using PCR-amplified nef fragment originating from nucleotide positions 8475 to $8900^{40}$ of $\mathrm{pNL} 4-3$. Amplification was accomplished with the following primer sets: forward primer (anneals upstream of nef and introduces the unique restriction site BamHI CCTAGG) 5'-GAGACAGAGACAGATCCATTCGATTA GTGAACGGATC-3' and reverse primer (anneals downstream of nef and introduces the unique restriction site ClaI TAGCTA) 5'-GCCATCGATATTGTTAGCTGCTGTATT GCTACTTGTG-3'.

Before overnight hybridization, nef probes were radiolabeled with $\left[\alpha-{ }^{32} \mathrm{P}\right] \mathrm{dCTP}$ using the Rediprime II DNA labeling system (GE Healthcare). Blots were rinsed afterward in wash buffer containing $2 \times$ saline sodium citrate (SSC) and $0.1 \%$ sodium dodecyl sulfate (SDS) for $10 \mathrm{~min}$, thrice, and finally in wash buffer containing $1 \times$ SSC and $0.1 \%$ SDS for 10 min. Radiolabeled RNA membrane was exposed to BioMax MS film (Kodak) overnight and developed for detectable RNA fragments. Relative density of each spliced fragment was analyzed using ImageJ software (http://rsbweb .nih.gov/ij).

\section{EGFP-Vpr infectious transfer for host cell entry}

HIV-1 ${ }_{\text {NL4-3 }}$ cDNA (1 $\mu \mathrm{g}$ WT or Rev-NoLS mutation) were co-expressed with $1 \mu \mathrm{g} \mathrm{pEGFP-Vpr}$ (NIH AIDS Research and Reference Reagent Program \#11386) in HEK293T (50\% confluent) within six-well culture plates. $\mathrm{CaCl}_{2}$ transfection media were replaced with $1 \mathrm{ml}$ supplemented DMEM $5 \mathrm{~h}$ later. Viral supernatant was collected $48 \mathrm{~h}$ afterward and quantified for p24 levels. One microgram p24 viral supernatant was used to infect $70 \%$ confluent CEM and HeLa T4 seeded in 12-well culture plates for $1.5 \mathrm{~h}$. Cells were cleared of virus with three rinses of $1 \times \mathrm{PBS}$, centrifugation at $1,000 \mathrm{rpm}$, and preserved in $3.7 \%$ paraformaldehyde. EGFP positivity was quantified using FACS. 


\section{$R T$ assay}

Viral supernatant containing WT or mutant HIV-1 $1_{\mathrm{NL} 4-3}$ was harvested $48 \mathrm{~h}$ after production in HEK293T cells. Supernatant was lysed to release intraviral RT. RT activity was measured as described in the Reverse Transcriptase Assay, colorimetric kit (Roche).

\section{Cre-loxP lentiviral dual reporter}

HEK293T cells were grown in $10 \mathrm{~cm}$ tissue culture plates to $50 \%$ confluency. SIN lentiviral backbone containing LoxP sites flanking CFP reporter with RFP reporter directly downstream (pBB-XCXR) was co-transfected $(15 \mu \mathrm{g})$ with packaging plasmids described. ${ }^{39}$ Transfection media were replaced with $6 \mathrm{ml}$ supplemented DMEM and $60 \mu \mathrm{l}(0.6 \mathrm{M})$ butyric acid $5 \mathrm{~h}$ post-transfection. Lentiviral supernatant was collected $48 \mathrm{~h}$ later and titrated through polybrene transduction $(4 \mu \mathrm{l} / \mathrm{ml})$ of HT1080 $\left(1 \times 10^{5}\right.$ cells/well in 12 -well plates).

A portion of transduced HT1080 was collected 5 days later, fixed in $4 \%$ paraformaldehyde, and CFP transduction multiplicity of infection of one viral copy per cell established through CyAn ADP 9 Color FACS. This HT1080-XCXR population was propagated and sorted based on CFP positivity for stable $\mathrm{BB}-X C X R$ reporter cells using BD AriaII SORP (COH Analytical Cytometry Facility).

Cre-loxP recombination reporter cells $(X C X R)$ were transduced with $10 \mu \mathrm{g}$ Cre-Vpr lentivirus (CVITG-Cre-VprIRES-Tat-GFP backbone) produced in HEK293T with WT or Rev-NoLS mutations. CFP transition to RFP from lentiviral transduction, in addition to GFP fluorescence from integration, was assessed with BD Fortessa Cytometer $(\mathrm{COH}$ Analytical Cytometry Facility) after preservation in $3.7 \%$ paraformaldehyde 7 days post-transduction. Integrase inhibitor-118-D-24 (20 $\mu \mathrm{m}$ in final volume) and RT inhibitor-AZT (NIH AIDS Research and Reference Reagent Program \#3485, $10 \mu \mathrm{m}$ in final volume)—-served as negative controls for $C V I T G$ reverse transcription and integration. HT1080 (-) and XCXR (-) reporter cells were used as negative controls for RFP, GFP, and CFP expression.

\section{Quantification of integrated proviral DNA by Alu-gag PCR}

Integrated viral DNA quantification was performed using Alu-gag PCR as described previously. ${ }^{41-45}$ Total genomic DNA was isolated from uninfected PBMC and HIV-infected cells using QIAamp DNA mini kit (Qiagen). The amount of isolated human genomes in the infected samples was determined by $\beta$-globin PCR using iTaq universal probe supermix (Bio-Rad). The PCR reactions were performed on CFX96 Real-Time PCR Detection System (Bio-Rad) for 40 cycles at following conditions: $95^{\circ} \mathrm{C}$ for $15 \mathrm{~s}$ and $60^{\circ} \mathrm{C}$ for $30 \mathrm{~s}$. The primer sequences are as follows: $\beta$-globin FP $5^{\prime}$-CCC TTG GAC CCA GAG GTT CT- $3^{\prime}$ and $\beta$-globin RP 5'-CGA GCA CTT TCT TGC CAT GA-3'. The genomic concentrations of samples were calculated by using a standard curve obtained from known dilution of PBMC DNA.

The genomic DNA samples were then diluted to $2 \mu \mathrm{g} / \mathrm{ml}$. Quantification of integrated DNA was performed by two-step Alu-gag nested PCR. The first step reaction was performed using OneTaq 2x Master Mix (New England Biolabs) on
C1000 Thermal Cycler (Bio-Rad) at following conditions: $95^{\circ} \mathrm{C}$ for $30 \mathrm{~s}, 40$ cycles of $95^{\circ} \mathrm{C}$ for $15 \mathrm{~s}, 50^{\circ} \mathrm{C}$ for $15 \mathrm{~s}$, and $68^{\circ} \mathrm{C}$ for $3.5 \mathrm{~min}$. The primer sequences are follows: Alu FP GCC TCC CAA AGT GCT GGG ATT ACA G-3' and gag RP 5'-GTT CCT GCT ATG TCA CTT CC-3'.

The product from the first step reaction was then subjected to the second step quantitative PCR (qPCR) to quantify integrated viral DNA. The qPCR reaction was performed on CFX96 Real-Time PCR Detection System (Bio-Rad) using iTaq universal probe supermix (Bio-Rad) for 40 cycles at following conditions: $95^{\circ} \mathrm{C}$ for $15 \mathrm{~s}$ and $60^{\circ} \mathrm{C}$ for $30 \mathrm{~s}$. The primer sequences are follows: RU5 FP 5'-TTA AGC CTC AAT AAA GCT TGC C-3' and RU5 RP 5'-GTT CGG GCG CCA CTG CTA GA-3'. Copy number of integrated viral DNA was calculated using a standard curve obtained from integration standard. ${ }^{41-45}$

\section{Immunoprecipitation}

HLfB was grown to $50 \%$ confluency in six-well culture plates and $\mathrm{CaCl}_{2}$ transfected with $5 \mu \mathrm{g} \mathrm{Rev-3'Flag} \mathrm{cDNA} \mathrm{per}$ well (WT and Rev-NoLS mutations). Total protein lysates were collected $48 \mathrm{~h}$ later with lysis buffer $(50 \mathrm{mM}$ Tris- $\mathrm{HCl}$ $\mathrm{pH} 8.0,137 \mathrm{mM} \mathrm{NaCl}$, and 1\% Triton-X 100) treated with protease inhibitor cocktail (Roche). One milligram per milliliter protein lysate was subjected to IP with $25 \mu$ prerinsed anti-Flag M2 affinity gel (Sigma-Aldrich) in lysis buffer for $2 \mathrm{~h}$, rotating at $4^{\circ} \mathrm{C}$. Flag beads were rinsed afterward $3 \times$ in lysis buffer and boiled at $95^{\circ} \mathrm{C}$ for $10 \mathrm{~min}$ in $50 \mu \mathrm{l} 2 \times$ sample loading buffer (without $\beta$-mercaptoethanol). Eluates were separated from anti-flag gel and analyzed through Western immunoblotting.

\section{Western immunoblot}

Protein eluates were subjected to an SDS-polyacrylamide gel electrophoresis (SDS-PAGE) 15\% acrylamide gel run, transferred onto PVDF transfer membrane (GE Healthcare), and incubated in blocking solution (5\% milk with $1 \times \mathrm{TBS}$ and $0.1 \%$ Tween-1 $1 \times$ TBST) for $1 \mathrm{~h}$ at room temperature. Membranes were submerged in primary antibodies diluted with blocking solution-B23 mouse monoclonal $\operatorname{IgG}_{1}$ (1:500, \#sc47725; Santa Cruz Biotechnologies)_and anti-Flag M2 mouse monoclonal $\operatorname{IgG}_{1}$ (1:1,000, \#F3165; Sigma-Aldrich) overnight at $4^{\circ} \mathrm{C}$ and rinsed $3 \times$ in $1 \times$ TBST.

Membranes were incubated in secondary goat-anti-mouse $\mathrm{IgG}_{1}$-horseradish peroxidase $(1: 5,000$; Santa Cruz Biotechnology) diluted in blocking solution for $1 \mathrm{~h}$ at room temperature, rinsed $3 \times$ with $1 \times$ TBST, and protein bands developed in enhanced chemiluminescence substrate (Pierce) for $5 \mathrm{~min}$. Protein chemiluminescence was detected upon exposure to BioMax MS film (Kodak) at varying time points, and relative density of protein signals was analyzed using ImageJ.

\section{Results}

Rev-NoLS requires two arginine residues for strict nucleolar access during HIV-1 production

Rev mutations lacking four amino acid residues from the NLS C-terminal end $\left({ }^{48} \mathrm{RQRQ}^{51}\right)$ were previously demonstrated to maintain nucleolar localization pattern in COS-7 cell lines; deletion mutations that extended three residues upstream 
$\left({ }^{45}\right.$ WRERQRQ $\left.{ }^{51}\right)$ exhibited nucleolar mislocalization. ${ }^{34} \mathrm{We}$ replicated these nucleolar mutations and examined localization pattern in the presence of HIV production. Rev-NoLS mutations containing amino acid deletions or single-point substitutions of each arginine residue within NoLS${ }^{45}$ WRERQRQ $^{51}$ - were generated and fused to enhanced green fluorescent protein (EGFP). Rev-EGFP fusion variants were examined for intracellular localization pattern within Rev-deficient HIV-1 $1_{\mathrm{HXB} 2}$ during proviral production (HLfB, Fig. 1).
Localization pattern of Rev-EGFP fusion variants was also examined in the absence of viral production (HeLa, Supplementary Fig. S1; Supplementary Data are available online at www.liebertpub.com/aid). Rev-NoLS maintaining two arginine residues after deletion (M8- $\Delta \mathrm{RQ}$ ) or glycine substitution (M4-R46G, M5-R48G, and M6-R50G) remained strictly nucleolar in pattern as WT Rev (Fig. 1A) during viral production.

In the absence of HIV-1, the nucleolar patterns of M4, M5, M6, and M8 were similar, however, included subnuclear distribution outside the nucleolus (Supplementary Fig. S1A).
A $\frac{\text { Rev-NoLS }}{45 \text { WRERQRQ }^{51}}$

WT Rev

M4 R46G

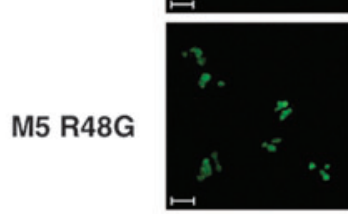

M6 R50G

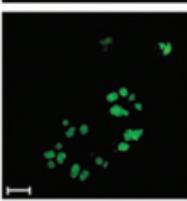

$\mathrm{M} 8 \mathrm{RQ}$

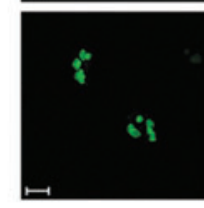

B
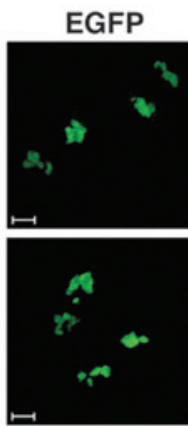
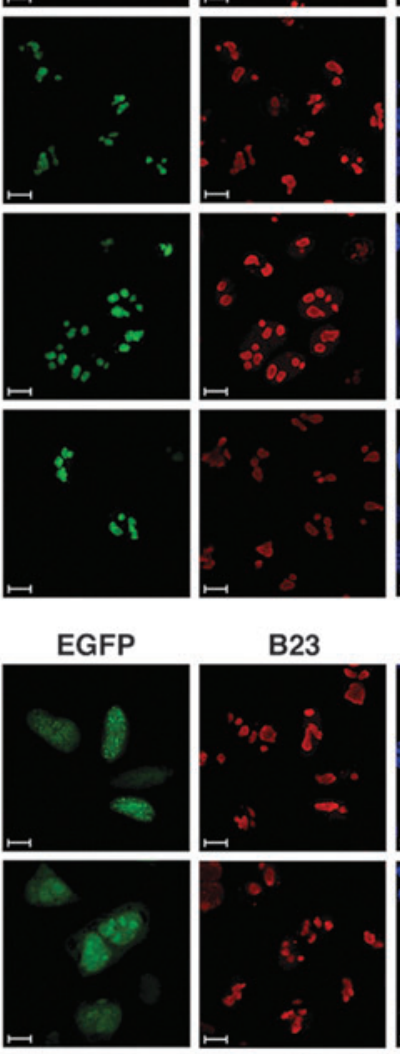

M2 R48,50G

M7 $\triangle$ WRERQRQ
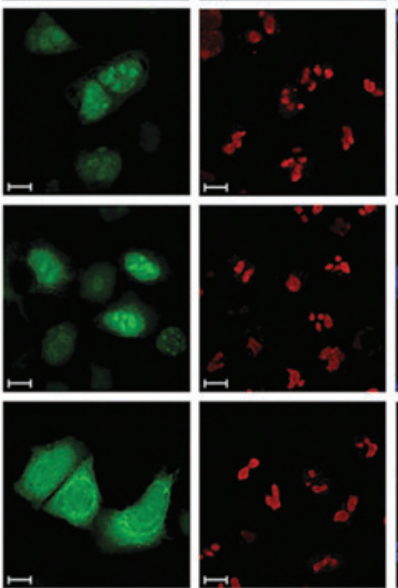

M9 R46,48,50G

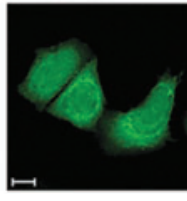

DAPI
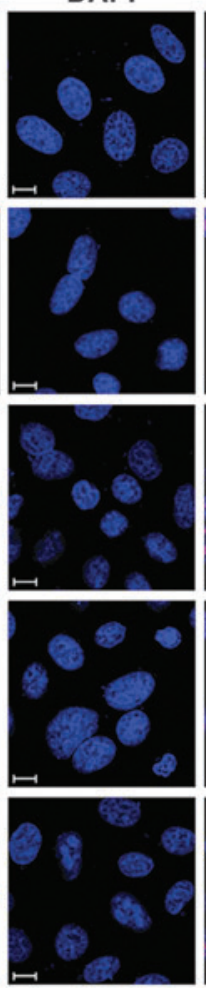

DAPI
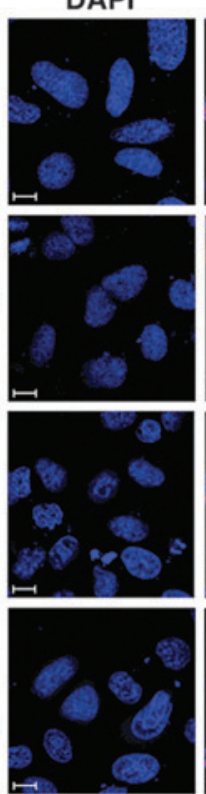

\section{Merged}
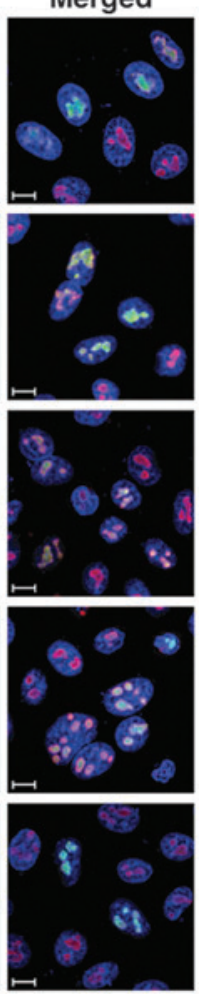

Merged
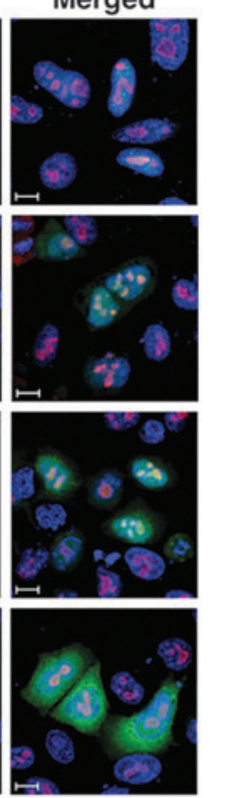

FIG. 1. Localization of RevNoLS mutations in the presence of HIV-1 $1_{\text {HXB2 } 2 \text { production. HLfB cells }}$ stably expressing Rev-deficient HIV-1 $1_{\text {HXB2 }}$ provirus were transfected with Rev-EGFP mutations (green), fixed, immunostained with anti-B23 nucleolar control (red), and treated with DAPI nuclear stain (blue). Rev-EGFP fusion mutations were examined for intracellular localization pattern and captured at 63× magnification, oil immersion $1.7 \times$ zoom, and represented against $10 \mu \mathrm{m}$ scale bars. (A) Similar to WT Rev, Rev-NoLS containing single-point mutations-M4, M5, and M6 - retained nucleolar access. Similarly, Rev-NoLS M8 retains nucleolar access in the presence of two arginine residues. (B) The absence of two arginine residues within the Rev-NoLS sequence causes nuclear and nucleolar dispersion (M1 and M2), nuclear distribution with deletion of NoLS (M7), and intracellular localization upon substitution of all three arginine residues within NoLS to glycine (M9). DAPI, 4',6-diamino-2-phenylindole; EGFP, enhanced green fluorescent protein; NoLS, nucleolar localization signal; WT, wild type. 
Rev-NoLS maintaining one arginine residue after deletion (M1- $\triangle \mathrm{RQRQ}$ ) and glycine substitution (M2-R48 and 50G) allowed nucleolar entry and caused nuclear dispersion of Rev (Fig. 1B). Similarly, M1 and M2 localized within nuclei and nucleoli in the absence of HIV-1 (Supplementary Fig. S1B). Rev-NoLS missing all arginine residues through deletion (M7- $\triangle$ WRERQRQ) caused nuclear dispersion during HIV$1_{\text {HXB2 }}$ production (Fig. 1B) and intracellular distribution without HIV-1 (Supplementary Fig. S1B). Glycine substitution of all arginine residues (M9-R46, 48, and 50G) resulted in nucleocytoplasmic distribution of Rev with HIV-1 (Fig. 1B) and nuclear localization without HIV-1 (Supplementary Fig. S1B).

\section{Functionality of Rev-NoLS mutations}

in HIV-1 $1_{\text {HXB2 }}$ production and RNA packaging

Functionality of Rev-NoLS mutations in the rescue of Rev deficiency during $\mathrm{HIV}-1_{\mathrm{HXB} 2}$ production was investigated in HLfB, which upon expression of WT Rev generates viral particles. ${ }^{46}$ Each Rev-EGFP NoLS variant was introduced into HLfB cells and viral particles collected $48 \mathrm{~h}$ afterward. Viral output of HIV-1 p24 capsid protein was quantified with enzyme-linked immunosorbent assay (ELISA) antigen capture assays (Fig. 2A).

Rev-NoLS mutations exhibiting non-nucleolar localization pattern in the nucleus and cytoplasm (M7 and M9) did not rescue viral production. Simultaneous nuclear and nucleolar access were also not sufficient for the rescue of viral production (M1 and M2).

Single-point mutations retaining strict nucleolar access (M4, M5, and M6) rescued viral production, although with reduced efficiency compared to WT. Rev-NoLS M8, which

FIG. 2. Functionality of Rev-NoLS mutations in HIV$1_{\text {HXB2 }}$ proliferation and RNA packaging. Rev-EGFP mutations were expressed within HLfB cells stably expressing Rev-deficient HIV-1 $1_{\text {HXB2 }}$ provirus. Viral supernatant was collected $48 \mathrm{~h}$ later and subjected to ELISA p24 antigen capture assays for the quantification of viral production. Viral supernatant was also quantified for the presence of HIV-1 $1_{\mathrm{HXB} 2}$ RNA using colorimetric bDNA assays incorporating probes specific to vif. In this system, WT Rev rescues Rev deficiency and leads to HIV-1 $1_{\mathrm{HXB} 2}$ proviral production (A). Rev-NoLS mutations lacking nucleolar access (M1, M2, M7, and M9) are nonfunctional in viral production. Rev-NoLS mutations maintaining nucleolar localization (M4, M5, and M6) produce HIV-1 $1_{\mathrm{HXB} 2}$; nucleolar M8 does not participate in viral production. (B) Nucleolar-localizing Rev-NoLS mutations (M4, M5, and M6), except M8, are capable of packaging $\mathrm{HIV}-1_{\mathrm{HXB} 2}$ RNA, yet not as efficiently as WT Rev. Mutants lacking strict nucleolar localization (M1, M2, M7, and M9) do not participate in viral RNA packaging. (C) Transfection efficiency of each Rev-NoLS mutation was quantified using EGFP FACS analysis and was used for the normalization of $\mathrm{HIV}-1_{\mathrm{HXB} 2}$ production $(\mathrm{p} 24, \mathrm{pg} / \mathrm{ml})$ and $\mathrm{HIV}-1_{\mathrm{HXB} 2}$ RNA packaging (RLU). Error bars represent the standard deviation of three biological replicates. bDNA, branched DNA; ELISA, enzyme-linked immunosorbent assay; FACS, fluorescent-activated cell sorting; RLU, relative light units. contains a deletion of two amino acid residues - arginine and glutamine $(\triangle \mathrm{RQ})$ - was strictly nucleolar, yet nonfunctional. p24 (pg/ml) was normalized to EGFP transfection efficiency (Fig. 2C).

Functionality of Rev-NoLS mutations was examined without EGFP fusion. Rev-NoLS mutations containing a 3'Flag tag were expressed in HLfB and viral supernatant collected $48 \mathrm{~h}$ later. Viral productivity through HIV-1 p24 capsid protein was quantified with ELISA antigen capture assays.
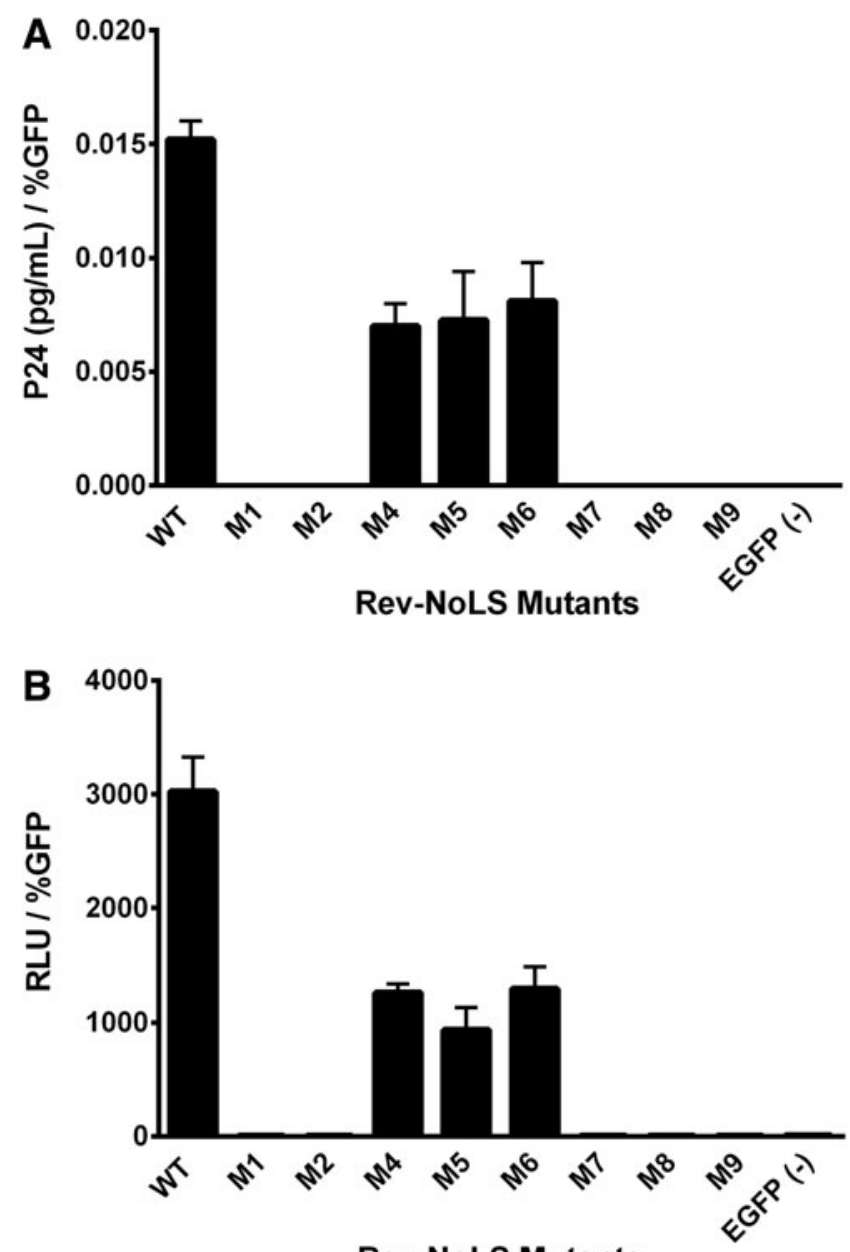

Rev-NoLS Mutants

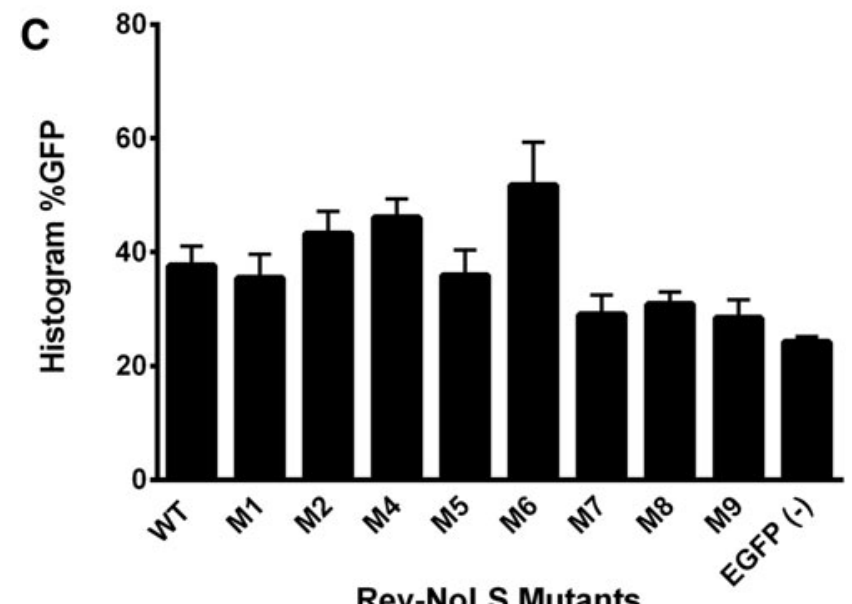

Rev-NoLS Mutants 
Similar results were observed without the EGFP tag (Supplementary Fig. S2A). EGFP fusion and the addition of the 3'Flag tag to Rev-NoLS mutations did not alter the function of Rev.

Rev mutations were next tested for ability to package viral RNA using branched DNA (bDNA) colorimetric assays and probes specific to HIV-1 vif. Each Rev-EGFP NoLS variant was introduced into HLfB cells and viral particles collected $48 \mathrm{~h}$ afterward. Intraviral RNA was detected in particles produced with nucleolar-localizing Rev mutations (M4, M5, and M6), however, with less efficiency than WT Rev (Fig. 2B). Nucleolar-specific M8, in addition to all other nuclear and cytoplasmic mutations, did not participate in RNA packaging during $\mathrm{HIV}-1_{\mathrm{HXB} 2}$ production. Intraviral RNA, represented as chemiluminescent relative light units, was normalized to EGFP transfection efficiency (Fig. 2C).

Rev-NoLS mutations without EGFP fusion were examined for ability to package intraviral RNA. Rev-NoLS mutations containing a $3^{\prime}$ Flag tag were expressed in HLfB and viral supernatant collected $48 \mathrm{~h}$ later. Intravirally packaged RNA was measured using bDNA colorimetric assays with probes specific to vif. Similar to Rev-EGFP, only nucleolarlocalizing single-point mutations (Rev-NoLS M4, M5, and M6), except Rev-NoLS M8, were able to package intraviral RNA (Supplementary Fig. S2B). Rescue in RNA packaging was not as efficient as WT Rev-3'Flag. Rev mutations shown to achieve simultaneous nuclear/nucleolar localization (RevNoLS M1 and M2) or cytoplasmic localization (Rev-NoLS M7 and M9) lost functionality in intraviral RNA packaging. EGFP fusion and 3'Flag tag addition did not alter the ability of RevNoLS mutations to package intraviral RNA.

\section{$H I V-1_{N L 4-3}$ harboring Rev nucleolar single-point mutations is unable to complete a full infectious cycle}

Mutations corresponding to Rev-NoLS M4, M5, M6, and M8 - all nucleolar in pattern - were induced within HIV $-1_{N L 4-3}$ cDNA (Supplementary Fig. S3) and used to propagate virus from HEK293T. Viral supernatant was collected $48 \mathrm{~h}$ later and quantified for p24 capsid through p24 ELISA antigen capture assays. Single-point mutations within HIV-1 $1_{\text {NL4-3 }}$ backbone (M4, M5, and M6) did not prevent viral production and the release of p24 (Fig. 3A). In comparison to WT HIV$1_{\mathrm{NL} 4-3}$, viral production of Rev-NoLS mutants decreased. Supernatant (20 ng p24) was subjected to bDNA assays using vif probe specific to packaged genomic RNA. Single-point mutations within HIV-1 $1_{\mathrm{NL} 4-3}$ backbone did not prevent genomic RNA packaging within viral particles (Fig. 3B). In comparison to WT HIV- $1_{\mathrm{NL} 4-3}, \mathrm{M} 8_{\mathrm{NL} 4-3}$ was unable to produce virus or package genomic RNA as efficiently as WT HIV- $1_{\text {NL4-3 }}$.

HIV $-1_{\text {NL4-3 }}$ particles harboring nucleolar mutations within the viral backbone were examined for infectivity of $\mathrm{CD}^{+}$ JLTRG-R5. JLTRG-R5 stably expresses LTR-EGFP, inducible upon Tat production after HIV-1 infection. ${ }^{47,48}$ Viral particles containing each of the single-point mutationsnucleolar-localizing Rev-NoLS M4, M5, and M6-were used to infect JLTRG-R5. HIV-1 $1_{\mathrm{NL} 4-3}$ backbone containing the nucleolar-localizing M8 deletion did not yield viral particles and was therefore used in this study as a negative control along with the $\mathrm{p} c D N A$ negative control. JLTRG-R5 was subjected to infection with $2 \mathrm{ng}$ p24 viral supernatant containing each HIV-1 $1_{\mathrm{NL} 4-3}$ variant and washed $24 \mathrm{~h}$ later with $2 \times$ HBSS (Hank's balanced salt solution). Infected cells were resupplemented in RPMI media. JLTRG-R5 was collected afterward at 5-day intervals postinfection.

HIV-infected cells were measured for EGFP positivity (inducible upon Tat expression after integration) using fluorescent-activated cell sorting (FACS) analysis. Unlike infectious WT HIV-1 $1_{\mathrm{NL} 4-3}$, variants of HIV-1 $1_{\mathrm{NL} 4-3}$ harboring single-point mutations (M4, M5, and M6) lacked the ability to replicate and produce abundant Tat for the internal activation of LTR-EGFP. Low frequency in LTR-EGFP activation after replication of $\mathrm{HIV}-1_{\mathrm{NL} 4-3}$ variants, unlike WT HIV $-1_{\text {NL4-3 }}$, was evident up to 20 days postinfection (Fig. 3C). During the replication peak at day $15, \mathrm{HIV}-1_{\mathrm{NL} 4-3}$ variants exhibited significant defects in replication compared to WT

FIG. 3. HIV-1 $1_{\mathrm{NL4}-3}$ harboring Rev nucleolar single-point mutations are unable to complete a full infectious cycle. Mutations corresponding to Rev-NoLS M4, M5, M6, and M8-all nucleolar in pattern-were induced within HIV-1 $1_{\text {NL4-3 }}$ cDNA and used to propagate virus. Virus was collected $48 \mathrm{~h}$ later and quantified using p24 ELISA antigen capture assays. Single-point mutations within HIV- $1_{\mathrm{NL} 4-3}$ backbone (M4, M5, and M6) allowed viral production to occur, however, not as efficiently as WT HIV-1 $1_{\text {NL4-3 }}$ (A). Viral supernatant (20 ng p24) was subjected to bDNA assays using probe specific to vif of packaged genomic RNA. Single-point mutations within HIV-1 ${ }_{N L 4-3}$ backbone did not prevent viral RNA packaging within viral particles (B). HIV-1 $1_{\mathrm{NL} 4-3}$ particles (2 ng p24 viral supernatant) harboring nucleolar mutations (M4, M5, and M6) within the viral backbone were examined for replication and infectivity of CD4 ${ }^{+}$JLTRG-R5 at 5-day intervals postinfection. HIV-infected cells were measured for EGFP positivity using FACS analysis. Unlike infectious WT HIV-1 $1_{\mathrm{NL} 4-3}$, HIV-1 ${ }_{\mathrm{NL} 4-3}$ variants lacked the ability to replicate up to 20 days postinfection $(\mathbf{C})$. HIV-1 $1_{\mathrm{NL} 4-3}$ variants exhibited defects in the ability to replicate and infect JLTRG-R5 compared to WT HIV-1 $1_{\mathrm{NL} 4-3}$, which infected $20 \%$ of the entire cell population at the day 15 infectious peak (D). HIV-1 $1_{\mathrm{NL} 4-3}$ variants replicated and infected host cells at extremely low frequency at the 15-day time point $\left(N=3\right.$ during unpaired $t$-tests, E). Quantification of infected JLTRG-R5 is as follows for WT versus HIV $1_{\mathrm{NL} 4-3}$ variants: M4 $p$ value $=.01$, M5 $p$ value $=.01$, and M6 $p$ value $=.01$. Ability of HIV-1 $1_{\mathrm{NL} 4-3}$ variants to gain function into the HIV-1 infectious cycle was monitored through p24 viral output. Viral supernatant from infected JLTRG-R5 was collected at 4-day intervals until 32 days postinfection. Unlike infectious WT HIV-1 ${ }_{\mathrm{NL} 4-3}$, HIV-1 $1_{\mathrm{NL} 4-3}$ variants lacked ability to fully regain functionality and infectivity up to 32 days postinfection $(\mathbf{F})$. This was also evident upon examination of genomic DNA harvested from HIV-infected JLTRG-R5 (WT HIV-1 ${ }_{\text {NL4-3 }}$ vs. single-point variants). Genomic DNA was collected every 5 days postinfection for 25 days and subjected to PCR amplification for detection of total HIV DNA and preintegrated 2-LTR circles. Total HIV DNA was undetectable from JLTRG-R5 infected with NL4-3 variants (M4, M5, M6, and M8), unlike detectable total HIV DNA from WT HIV-1 NL4-3 $_{3}$ starting at day 15 (G). Preintegrated 2-LTR circles accumulated in the presence of WT HIV-1 $1_{\mathrm{NL} 4-3}$ infection beginning at day $15 ; 2$-LTR circles were not detected in DNA genomic samples from the NL4-3 variants. Gel loading controls were obtained through amplification of $\beta$-globin DNA. PCR, polymerase chain reaction; ${ }^{*} p<.05$ 

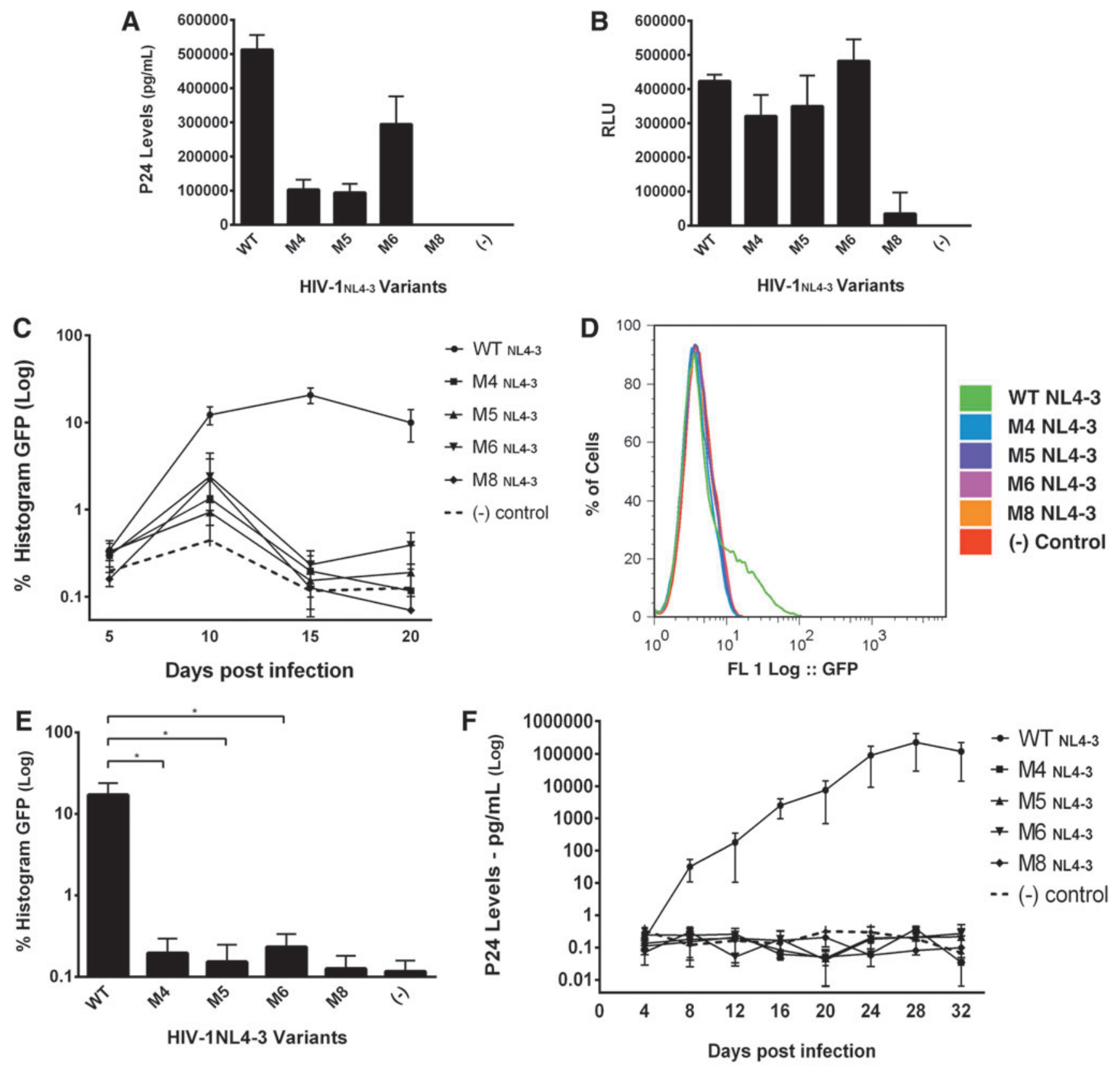

G

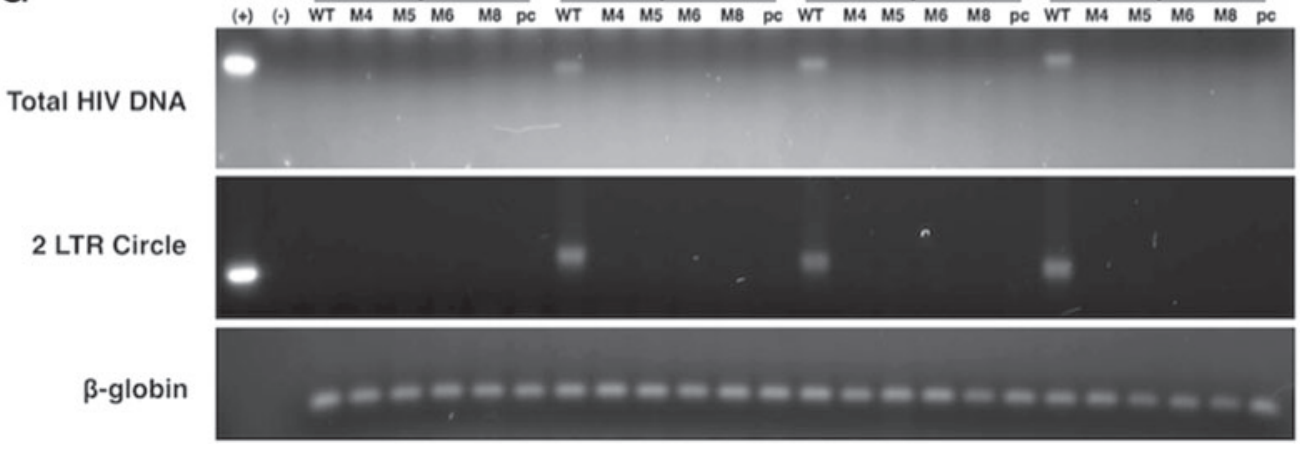


HIV $-1_{\text {NL4-3 }}$, which was able to replicate and infect $20 \%$ of the entire cell population (Fig. $3 \mathrm{D}$ ). HIV-1 $1_{\mathrm{NL} 4-3}$ variants infected host cells at extremely low frequency at the 15-day time point (Fig. 3E).

Quantification of infected JLTRG-R5 is as follows for $\mathrm{WT}$ versus $\mathrm{HIV}-1_{\mathrm{NL} 4-3}$ variants: $\mathrm{M} 4 p$ value $=.01, \mathrm{M} 5 p$ value $=$ .01 , and M6 $p$ value $=.01$. Each column represents a sample size of three individual infectious processes during unpaired $t$-tests.

Ability of HIV-1 $1_{\mathrm{NL} 4-3}$ variants to gain function into the HIV-1 infectious cycle was monitored through p24 viral output. Viral supernatant from JLTRG-R5 was collected at 4-day intervals until 32 days postinfection. Unlike infectious WT HIV-1 $1_{\mathrm{NL4}-3}$ exhibiting active viremia, HIV-1 $1_{\mathrm{NL} 4-3}$ variants lacked the ability to fully regain functionality and infectivity up to 32 days postinfection (Fig. 3F).

This was also evident upon examination of genomic DNA harvested from HIV-infected JLTRG-R5 (WT HIV-1 NL4-3 $_{\text {vs. }}$ single-point variants). Genomic DNA was collected every 5 days postinfection for 25 days and subjected to polymerase chain reaction (PCR) amplification for detection of total HIV DNA and preintegrated 2-LTR circles. Total HIV DNA was undetectable from JLTRG-R5 infected with HIV-1 $1_{\mathrm{NL} 4-3}$ variants (M4, M5, M6, and M8), unlike detectable total HIV DNA from WT HIV $-1_{\text {NL4-3 }}$ starting at day 15 and beyond (Fig. 3G). WT HIV DNA was undetectable up to 10 days postinfection. Similarly, preintegrated 2-LTR circles were not detected in DNA genomic samples from the HIV-1 $1_{\mathrm{NL} 4-3}$ variants; 2 -LTR circles accumulated in the presence of WT HIV-1 $1_{\mathrm{NL} 4-3}$ infection beginning at day 15 . Gel loading controls were obtained through amplification of $\beta$-globin DNA.

\section{Lentivirus generated with nucleolar-localizing Rev mutations is transducible at extremely low frequency}

Lentiviral backbones lacking the following genes: $\mathrm{gag} / \mathrm{pol}$, vif, $v p u$, env, and nef were developed previously for safe delivery of therapeutic genes and small interfering RNAs inhibiting HIV-1 infection. ${ }^{38,39,49}$ Lentiviral HIV7/CMV$G F P$ vector containing a GFP reporter for quantification of transduction events (Fig. 4A) was co-expressed with packaging vectors, including Rev-NoLS mutations (M4, M5, and M6), in HEK293T. Viral supernatant was collected $48 \mathrm{~h}$ afterward and normalized to $500 \mathrm{pg}$ p 24 before the transduction of HT1080 (Fig. 4B).

Rev M8, previously shown to lack function in viral production and viral RNA packaging, was analyzed as a negative control. Viral particles were introduced into HT1080 cells, and transduced cells quantified $48 \mathrm{~h}$ later using EGFP FACS analysis. Lentivirus packaged with Rev-NoLS mutations exhibited significantly defective transduction below $6 \%$ in comparison to lentivirus packaged with WT Rev, in which $40 \%$ of HT1080 were transduced (Fig. 4C, D). Each column represents a sample size of six separate transduction events during unpaired $t$-tests (Fig. 4D).

\section{Rev single-point nucleolar mutations lead} to irregularities in $\mathrm{HIV}-1_{N L 4-3} m R N A$ splicing

Nucleolar mutations of interest resulting in proviral production (Rev-NoLS M4, M5, and M6) were examined further to identify the step of the HIV-1 infectious cycle interrupted in the presence of Rev-NoLS mutations. The HIV-1 mRNA splicing machinery was initially examined, as HIV-1 mRNA splicing is dependent on the host mRNA-splicing machinery to produce three mRNA species for expression of proteins required in viral assembly and release - unspliced $9 \mathrm{~kb}$ mRNA, partially spliced $4 \mathrm{~kb}$ mRNA, and fully spliced $2 \mathrm{~kb}$ mRNA. Upon infection and viral integration into host genomes, fully spliced viral mRNA leads to expression of Tat, Rev, and Nef. Rev in turn achieves nucleocytoplasmic transport of RREcontaining RNAs through affinity with CRM1, involved in an mRNA-independent nuclear export pathway. ${ }^{50}$

Rev transports partially spliced viral mRNA to the cytoplasm for expression of Vif, Vpr, and Vpu accessory proteins. Rev additionally stabilizes and transports unspliced viral mRNA to encode Gag and Gag-/Pol-derived proteins; unspliced HIV mRNA serves as viral genomic RNA to be packaged within viral particles for release and re-infection of other hosts. It is currently unknown if HIV-1 mRNA stabilization for this process involves a nucleolar pathway mediated by the nucleocytoplasmic activity of Rev. Rev-NoLS single-point mutations and deletions corresponding to nucleolar-localizing M4, M5, M6, and M8 were induced within the HIV-1 $1_{\text {NL4-3 }}$ backbone. HIV-1 mRNA splicing was observed as a result of nucleolar mutations to further understand the role of the nucleolus on viral mRNA splicing.

Single-point mutations incorporating glycine in replacement of arginine residues were induced within the $\mathrm{cDNA}$ of HIV $-1_{\mathrm{NL} 4-3}$ Rev-NoLS motif (M4, M5, and M6). Deletion of the last two amino acids of Rev-NoLS (M8) was also generated. Expression plasmid containing HIV-1 ${ }_{\text {NL4-3 }}$ RevNoLS mutations was transfected into HEK293T and total RNA collected $48 \mathrm{~h}$ later. Total RNA $(40 \mu \mathrm{g})$ was subjected to Northern blot analysis for the detection of HIV splice variants (unspliced $9 \mathrm{~kb}$, partially spliced $4 \mathrm{~kb}$, and unspliced $2 \mathrm{~kb}$ ) using radiolabeled probe specific to nef (Fig. 5A). Ribosomal RNA loading controls (60S and 40S) were captured before blot transfer and used as standards in densitometry of three independent experimental blots.

Unpaired $t$-tests $(N=6)$ were used in the statistical analyses of WT mRNA versus Rev-NoLS mutant mRNA. Relative density of unspliced Rev-NoLS variant expression $\left(\mathrm{M} 4_{\mathrm{NL} 4-3}\right.$, $\mathrm{M}_{\mathrm{NL4}-3}$, and $\mathrm{M6}_{\mathrm{NL4}-3}$ ) reduced significantly in comparison to unspliced WT mRNA; unspliced $\mathrm{M} 8_{\mathrm{NL} 4-3}$ mRNA was similar in expression to unspliced WT mRNA (Fig. 5B). Partially spliced HIV- $1_{\text {NL4-3 }}$ mRNA of WT and Rev-NoLS variants $\left(\mathrm{M} 4_{\mathrm{NL} 4-3}, \mathrm{M} 5_{\mathrm{NL} 4-3}, \mathrm{M} 6_{\mathrm{NL} 4-3}\right)$ was similar in relative density, unlike abundant M $8_{\mathrm{NL}-3}$ mRNA (Fig. 5C). Fully spliced mRNA of $\mathrm{M}_{\mathrm{NL4}-3}$ and $\mathrm{M} 8_{\mathrm{NL} 4-3}$ was significantly abundant compared to fully spliced WT mRNA (Fig. 5D). $\mathrm{M} 4_{\mathrm{NL} 4-3}$ and $\mathrm{M} 5_{\mathrm{NL} 4-3}$ relative densities were comparable to fully spliced WT mRNA ratio.

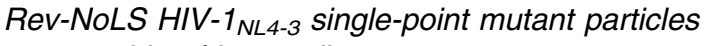 are capable of host cell entry}

Despite nucleolar mutations, HIV- $1_{\mathrm{NL} 4-3}$ particles resembled WT in the ability to replicate and package intraviral RNA. We next tested the ability of mutant viral particles to achieve host cell entry, quantified through intraviral EGFP-Vpr infectious transfer. The direct cellular uptake of HIV-1 virions to the CD4 surface receptor has been observed with fluorescence microscopy by copackaging EGFP-Vpr fusion protein to create $\mathrm{GFP}^{+} \mathrm{HIV}$ 

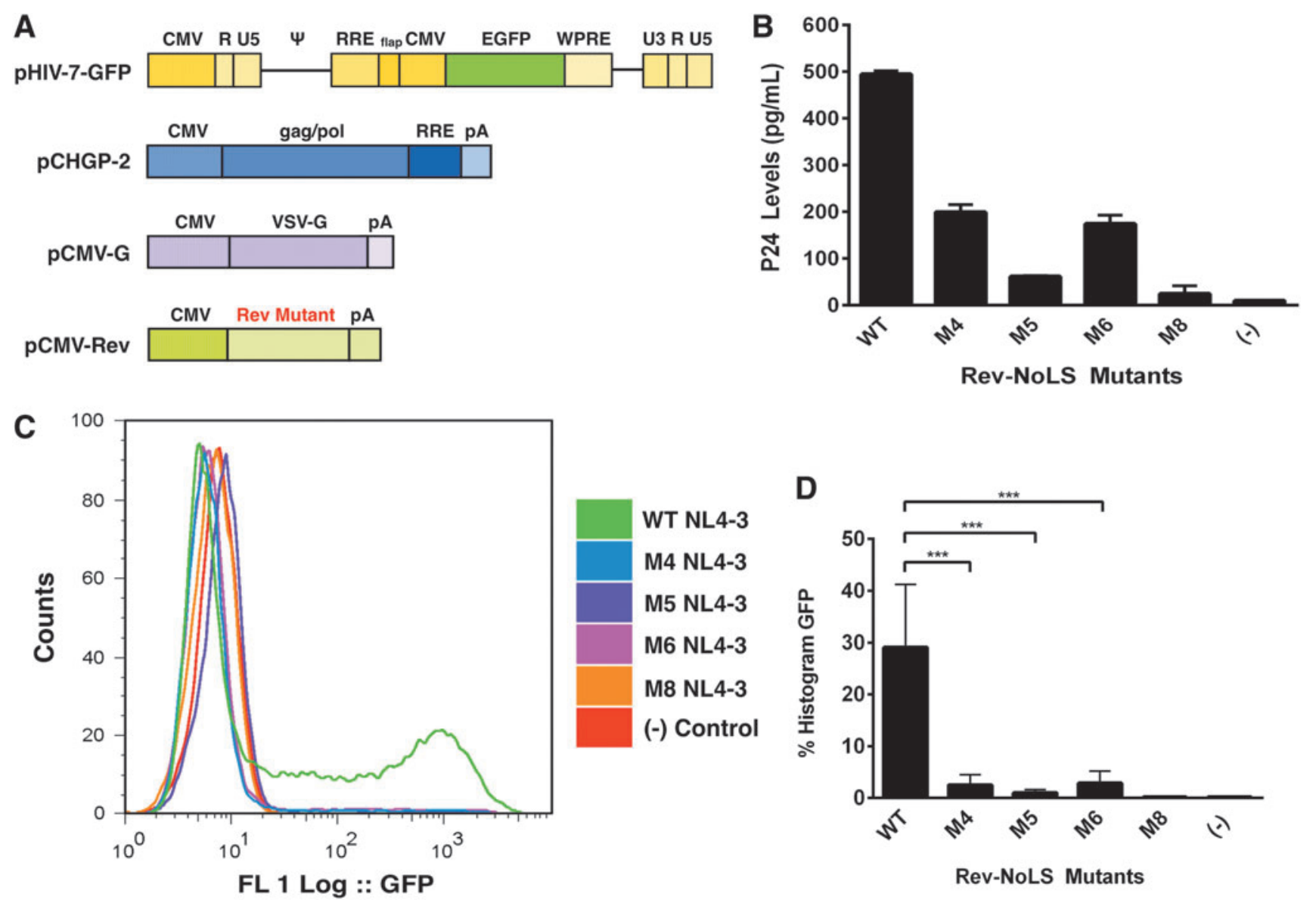

FIG. 4. Transducibility of HIV/7-C-GFP lentivirus packaged with nucleolar-localizing Rev-NoLS mutations. Lentiviral $H I V 7 / C M V$-GFP vector was co-expressed with packaging vectors, including $\alpha$-flag-tagged Rev-NoLS mutations (M4, M5, and M6), in HEK293T (A). Supernatant containing lentivirus produced with each $\alpha$-flag-tagged Rev-NoLS mutation was collected and quantified using p24 antigen capture assays (B). Lentivirus was normalized to $500 \mathrm{pg}$ p24 and used to transduce HT1080. Transduced cells were washed and fixed $48 \mathrm{~h}$ later, and quantified for GFP expression using FACS analysis. Lentivirus packaged with nucleolar Rev mutations is transducible at extremely low frequency ( $p$ values of $\mathrm{M} 4=.0004, \mathrm{M} 5=.0002$, and M6=.0004), unlike lentivirus produced with WT-Rev $(\mathbf{C}, \mathbf{D}) . * * * p<.001$.

particles. ${ }^{51}$ EGFP-Vpr was later utilized to monitor virion uptake into $\mathrm{CD}^{+}$and $\mathrm{CD}^{-}{ }^{-} \mathrm{HeLa}$ cells during HIV-1 Nef regulation of viral entry into the host cytoplasm. ${ }^{52}$

Thus, we implemented this technique to quantify the cellular uptake of GFP ${ }^{+}$HIV-1 particles co-packaged with our

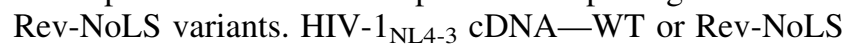
variants-was co-packaged with EGFP-vpr vector to propagate fluorescent viral particles. CEM and $\mathrm{CD} 4^{+} \mathrm{HeLa}$ T4 cells were subjected to infection with $1 \mu \mathrm{g}$ p24 supernatant for $1.5 \mathrm{~h}$, preserved, and quantified for EGFP positivity using FACS analysis. Despite the nucleolar single-point mutations, viral particles are as capable of host cell entry as WT HIV$1_{\text {NL4-3 }}$ in CEM (Supplementary Fig. S4A) and HeLa T4 cells (Supplementary Fig. S4B). Quantification of host cells with EGFP-Vpr-M8 NL4-3 contained fluorescent background comparable to pcDNA (-) control.

\section{Rev-NoLS HIV-1 NL4-3 $_{\text {single-point mutant particles }}$} are able to achieve reverse transcription

Mutations corresponding to Rev-NoLS M4, M5, M6, and M8-all nucleolar in pattern — were generated within HIV-
$1_{\mathrm{NL4}-3} \mathrm{cDNA}$ and used to propagate virus in HEK293T culture. Single-point $\mathrm{HIV}-1_{\mathrm{NL} 4-3}$ particles were normalized to $20 \mathrm{ng}$ of p24 supernatant and examined intravirally for functional reverse transcriptase (RT) using a colorimetric RT kit. HIV-1 $1_{\text {NL4-3 }}$ variants were able to produce and package functional RT (M4, M5, and M6), unlike M8 and pcDNA negative controls absent in RT activity (Supplementary Fig. S5). Colorimetric values represent DNA concentration (ng) after release of RT from viral particles and reverse transcription thereafter.

\section{Cre-loxP dual fluorescent reporters indicate lentiviral entry, reverse transcription, and integration in the background of Rev-NoLS mutations}

As another test for viral entry, reverse transcription, and integration of virus packaged with the Rev-NoLS variants, we designed a new system based on the ability to detect viral entry using virus carrying EGFP-Vpr fusion protein. We created a reporter cell line of HT1080 cells integrated with a LoxP-mCFP-LoxP-TagRFP (HT1080-XCXR) gene cassette, which would undergo an mCFP (cyan) to TagRFP 
A
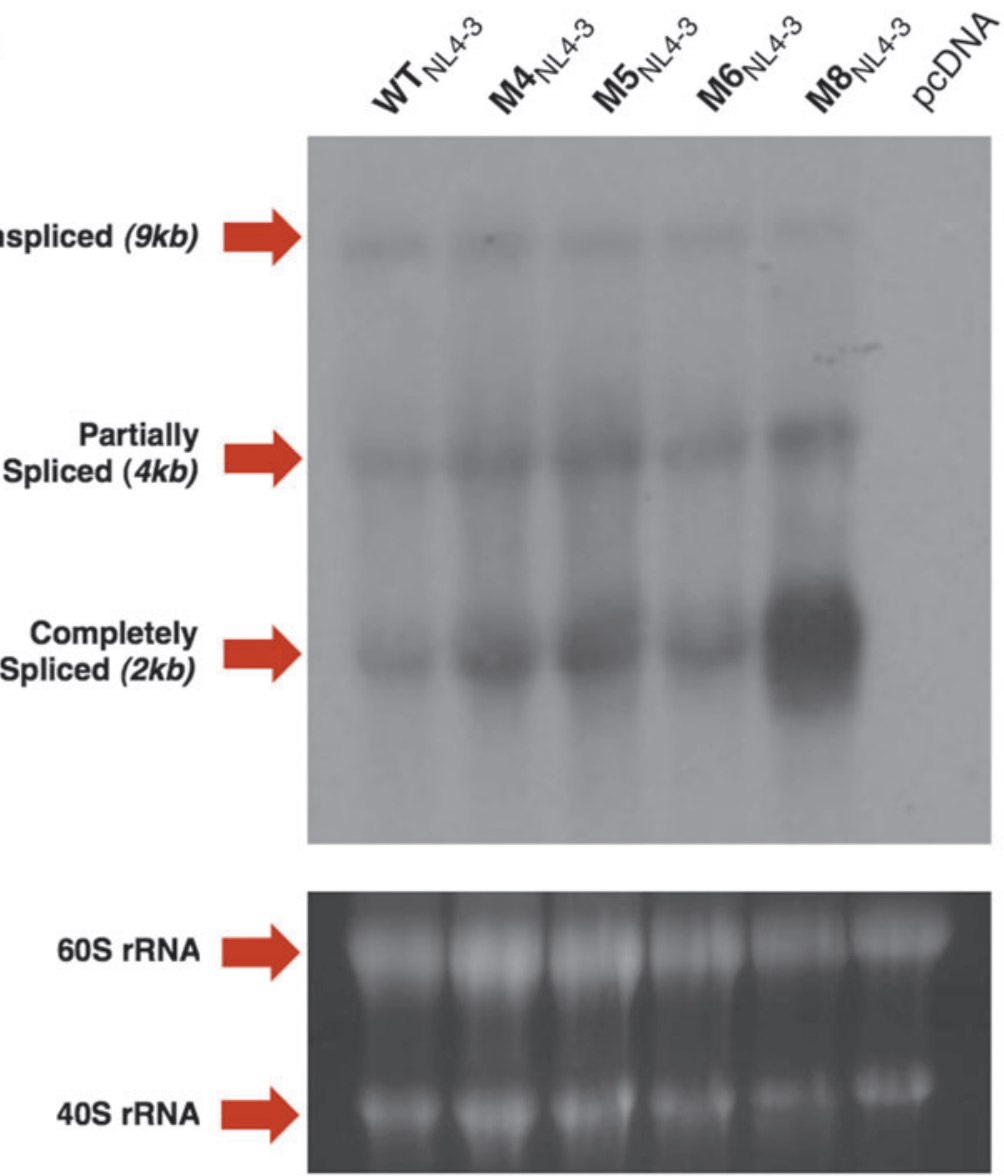
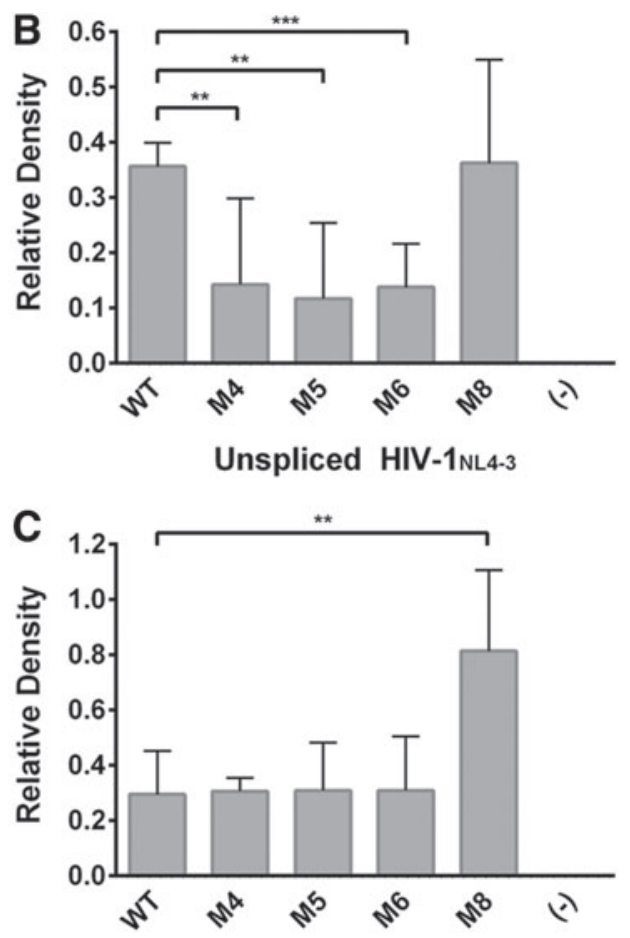

Partially Spliced HIV-1NL4-3

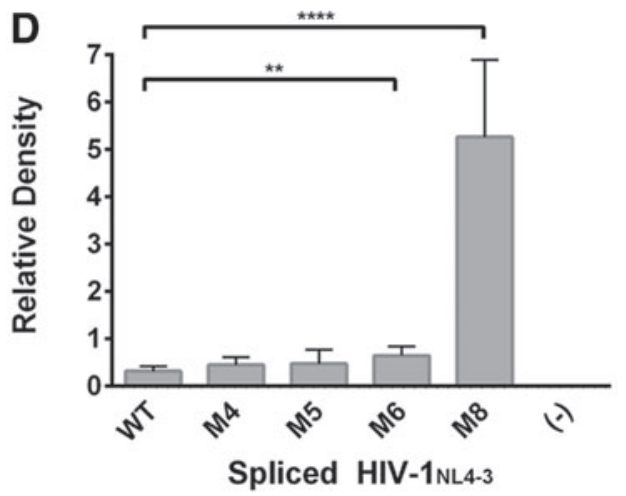

FIG. 5. Northern blot analysis of HIV-1 $1_{\mathrm{NL} 4-3}$ in the presence of Rev-NoLS mutations. pNL3-4 plasmid was transfected into HEK293T culture and total RNA collected $48 \mathrm{~h}$ later. Total RNA (40 $\mu \mathrm{g})$ collected during HIV- $1_{\mathrm{NL} 4-3}$ propagation in HEK293T was subjected to Northern blot analyses using radiolabeled Nef probe. The known spliced variants of HIV-1 mRNA in lane $1-\mathrm{WT}$ (9 kb unspliced, $4 \mathrm{~kb}$ partially spliced, and $2 \mathrm{~kb}$ spliced) were compared to HIV-1 $1_{\mathrm{NL} 4-3}$ variants harboring Rev-NoLS single-point mutations (lane 2: $\mathrm{M}_{\mathrm{NL} 4-3}$, lane 3: $\mathrm{M}_{\mathrm{NL} 4-3}$, lane 4: $\mathrm{M}_{\mathrm{NL} 4-3}$, lane 5 : $\mathrm{M}_{\mathrm{NL} 4-3}$, and lane 6: pcDNA) (A). rRNA 60s and 40s were used as loading controls. Unspliced, partially spliced, and fully spliced HIV-1 mRNA expression were analyzed from three Northern blotting experiments using ImageJ software. Relative density of WT unspliced HIV-1 $1_{\mathrm{NL} 4-3}$ mRNA was compared to HIV-1 $1_{\mathrm{NL} 4-3}$ variants harboring single-point Rev-NoLS mutations within the viral backbone $($ M4 $p$ value $=.009$, M5 $p$ value $=.0003$, and M6 $p$ value $=.0004)(\mathbf{B})$. Unspliced mRNA contains Gag/Pol genes. Relative density of WT partially spliced HIV $-1_{\mathrm{NL} 4-3}$ mRNA was compared to HIV-1 $1_{\mathrm{NL} 4-3}$ Rev-NoLS variants (M8 $p$ value $=.003)(\mathbf{C})$. Partially spliced mRNA contains $e n v$, vif, and $v p r$ genes. Relative density comparing WT fully spliced HIV $-1_{\text {NL4-3 }}$ mRNA expression was compared to HIV-1 $1_{\text {NL4-3 }}$ Rev-NoLS variants $($ M6 $p$ value $=.008$ and M8 $p$ value $<.0001$ ) (D). Fully spliced mRNA contains Tat, Rev, and Nef genes. **p<.01, *** $p<.001, * * * * p<.0001$.

(red) conversion upon the delivery or expression of Cre protein (Fig. 6A). In this new system, we wanted to test for viral entry, reverse transcription, and transgene integration into infected cells. Thus, we created a Cre-Vpr fusion protein that was expressed from a Tat-responsive lentiviral vector (HIV LTR-Cre-Vpr fusion-IRES-Tat/GFP fusion or CVITG) (Fig. 6B).
Therefore, entry of the CVITG virus carrying Cre-Vpr fusion protein would induce a conversion from mCFP expression to TagRFP expression, while successful integration of the CVITG virus would also lead to GFP production. CVITG lentiviral vector was co-expressed with packaging vectors, including $\alpha$-flag-tagged Rev-NoLS mutations (M4, M5, and M6) in HEK293T. 
Viral supernatant was collected $48 \mathrm{~h}$ later and quantified using p24 ELISA antigen capture assays. Rev-NoLS mutations function in CVITG lentiviral production, yet not as efficiently as WT Rev (Fig. 6C). Cre-loxP recombination reporter cells (HT1080-XCXR) were transduced with $10 \mu \mathrm{g}$ CVITG Cre-Vpr lentivirus produced using WT or Rev-NoLS mutations (M4, M5, and M6). Cyan fluorescent protein (CFP) transition to red fluorescent protein (RFP) from lentiviral transduction, in addition to GFP fluorescence from integration, was assessed using FACS analysis.

From these experiments, we observed that CVITG virus co-packaged with M4, M5, and M6 Rev variants was able to induce TagRFP expression at extremely low frequency-an indicator of lentiviral entry (Fig. 6D, E). CVITG virus copackaged with M4, M5, and M6 Rev variants was also able to induce Tat/GFP expression at extremely low frequency-an indicator of lentiviral reverse transcription and integration (Supplementary Fig. S6A, B) in a small fraction of cells.

Lentivirus co-packaged with Rev variant M8 did not induce viral entry, reverse transcription, or integration similar to pcDNA negative control. Control experiments using WT Rev with RT inhibitor (azidothymidine [AZT]) and/or integrase (IN) inhibitor (118-D-24) demonstrated the functionality of the system to detect either viral entry $\left(\mathrm{RFP}^{+}\right.$and $\mathrm{GFP}^{-}$cells, Fig. 6F, G) or expression of Cre and integration $\left(\mathrm{RFP}^{+}\right.$and $\mathrm{GFP}^{+}$cells, Supplementary Fig. S6C, D).

\section{Rev nucleolar mutations lead to the deregulation of HIV-1 ${ }_{N L 4-3}$ integration}

Supernatant of HIV-1 $1_{\mathrm{NL} 4-3}-\mathrm{WT}$ and Rev-NoLS variants M4, M5, and M6-was normalized to $20 \mathrm{ng}$ capsid p24 for infection of JLTRG-R5 populated at $1 \times 10^{6}$ cells per well of 12 -well tissue culture plates. Cells were harvested for genomic DNA starting 6, 12, 24, and $48 \mathrm{~h}$ postinfection. The genomic DNA samples were diluted to $2 \mu \mathrm{g} / \mathrm{ml}$ and quantified for integrated viral DNA using a two-step Alu-gag PCR described previously. ${ }^{41-45}$ Copy number of integrated viral DNA was calculated using a standard curve obtained from integration standard consisting of JLTRG-R5 infected with WT HIV-1 $1_{\mathrm{NL} 4-3}$. Viral integration of HIV-1 $1_{\mathrm{NL} 4-3}$ variants (M4 and M5) occurred at extremely higher frequency than WT HIV-1 ${ }_{\text {NL4-3 }}$ beginning $6 \mathrm{~h}$ after infection (Fig. 7). Variant M6 exhibited similar integration copies to that of WT.
Integrated copies were detected at lower frequency starting $12 \mathrm{~h}$ postinfection and continued to decrease gradually until the 48-h time point after viral infection. Supernatant of pCDNA was used as a negative control for integration in these studies.

\section{Rev-NoLS single-point mutations lose interaction with B23 during viral production}

Nucleolar B23 has high affinity to Rev-NoLS and functions in nucleolar localization of $\mathrm{Rev}^{53}$ and nucleocytoplasmic transport of Rev-bound HIV mRNAs. ${ }^{54}$ The affinity of B23 with Rev containing single-point arginine substitutions and deletion was assessed through immunoprecipitation (IP) of Rev-3'Flag (WT and mutations) and Western immunoblotting. HLFB were transfected with Rev-NoLS mutations (M4, M5, M6, and M8). Protein extract for IP reaction $(1 \mathrm{mg} / \mathrm{ml})$ was collected from HLFB after $48 \mathrm{~h}$ of $\mathrm{HIV}-1_{\mathrm{HXB} 2}$ production. IP eluates were subjected to Western immunoblotting using monoclonal antibodies specific to $\alpha$-Flag-Rev (Fig. 8A-C) and B23 (Fig. 8B).

In the background of Rev single-point mutations (RevNoLS M4, M5, and M6), B23 binding affinity was significantly reduced (Fig. 8D). B23 maintained affinity with WT Rev during HIV production. Each column represents a sample size of three IP experiments, compared during unpaired $t$-tests.

\section{Discussion}

\section{Rev-NoLS in viral production and infection}

Deletion of amino acids 48-51 (RQRQ) from the C-terminal end of the Rev-NoLS maintained nucleolar accumulation in COS-7 culture. Deletion of the entire Rev-NoLS (amino acids 45-51, WRERQRQ) caused the intracellular dispersion of Rev. ${ }^{34}$ In our current model, removal of amino acids 48-51 (M1-RQRQ) from Rev-EGFP resulted in the nucleolar/nuclear accumulation of Rev during HIV-1 production in HeLa culture expressing Rev-deficient proviral HIV-1 $1_{\mathrm{HXB} 2}$. Similarly, nucleolar/nuclear accumulation was observed upon removal of the entire NoLS (M7-WRERQRQ).

Differences in subcellular localization in the previous study in comparison to this observation are attributed to the presence of an HIV-1 production model. In the absence of viral production in HeLa culture, removal of amino acids 48-51 (Rev-

FIG. 6. Cre-loxP dual fluorescent reporters indicate lentiviral entry, reverse transcription, and integration in the background of Rev-NoLS mutations. An HT1080 reporter cell line was generated to test for viral entry, reverse transcription, and transgene integration. HT1080 reporters contain a LoxP-mCFP-LoxP-TagRFP (XCXR) gene cassette, which undergoes conversion from mCFP (cyan) to TagRFP (red) upon the viral delivery of Cre protein (A). The viral delivery system packages Cre-Vpr fusion protein expressed from a Tat-responsive lentiviral vector (HIV LTR-Cre-Vpr fusion-IRES-Tat/ GFP fusion or CVITG) (B). CVITG lentiviral vector was co-expressed with Gag/Pol and VSV-G packaging vectors ${ }^{91}$, and $\alpha$-flag-tagged Rev-NoLS mutations (M4, M5, and M6) in HEK293T. Viral supernatant was collected 48h later and quantified using p24 ELISA antigen capture assays. Rev-NoLS mutations M4, M5, and M6 function in lentiviral production, but not as efficiently as WT Rev (C). XCXR were transduced with $10 \mu \mathrm{g} C$ VITG Cre-Vpr lentivirus. CFP transition to RFP from lentiviral transduction was assessed using FACS analysis 7 days post-transduction. $C V I T G$ lentivirus co-packaged with M4, M5, and M6 Rev variants induced TagRFP expression at extremely low frequency; this was an indicator of lentiviral entry $(\mathbf{D}, \mathbf{E})$. Control experiments using WT Rev with reverse transcriptase inhibitor (AZT) and/or integrase inhibitor (118-D-24) served as negative controls for CVITG transduction, and demonstrated the functionality of the system to detect viral entry, reverse transcription, and integration (F, G). HT1080 (-) represents an additional cell population used as negative controls for RFP and CFP expression. $X C X R(-)$ represents a negative control population of reporter cells that are not transduced with CVITG lentivirus. AZT, azidothymidine; CFP, cyan fluorescent protein; RFP, red fluorescent protein. 
A LoxP ECFP Reporter Before Entry of Cre Lentivirus

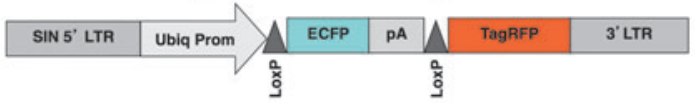

Cre-LoxP-induced RFP Reporter After Lentiviral Entry
B

Cre / Vpr Lentiviral Backbone

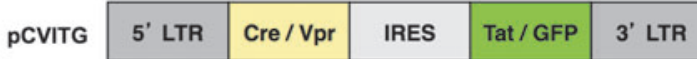
3' LTR

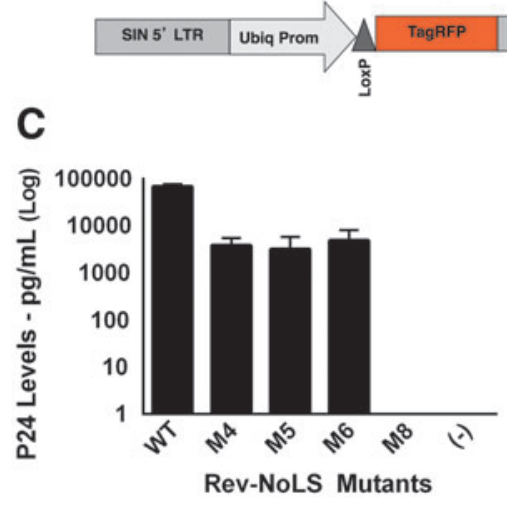

E

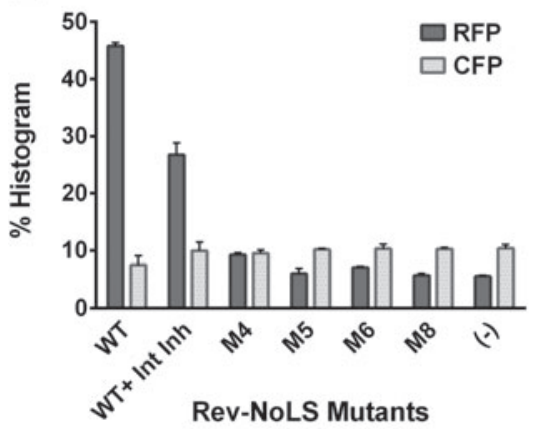

D
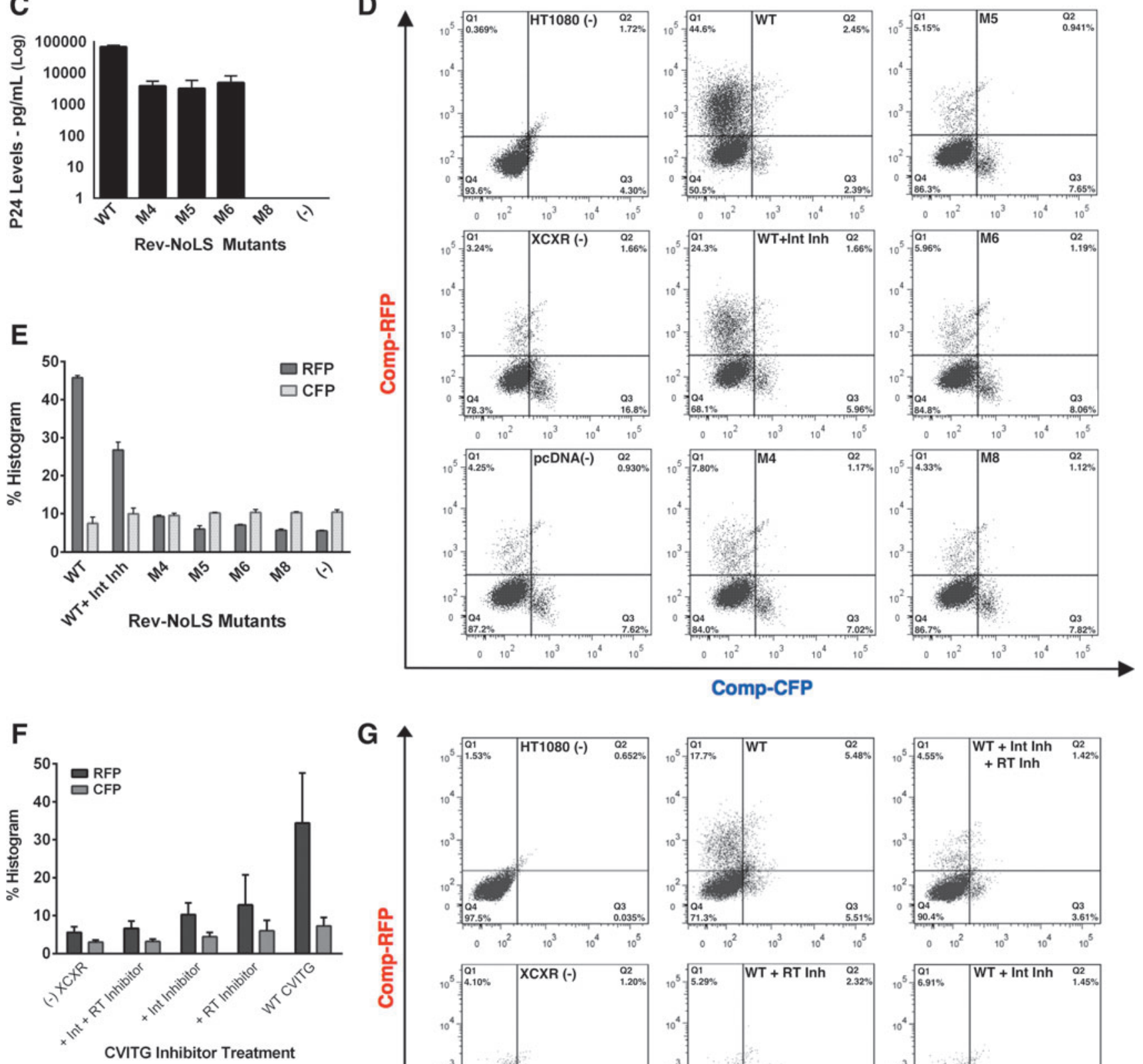

G

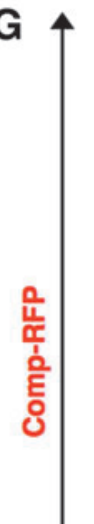

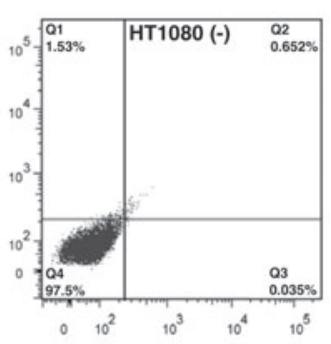
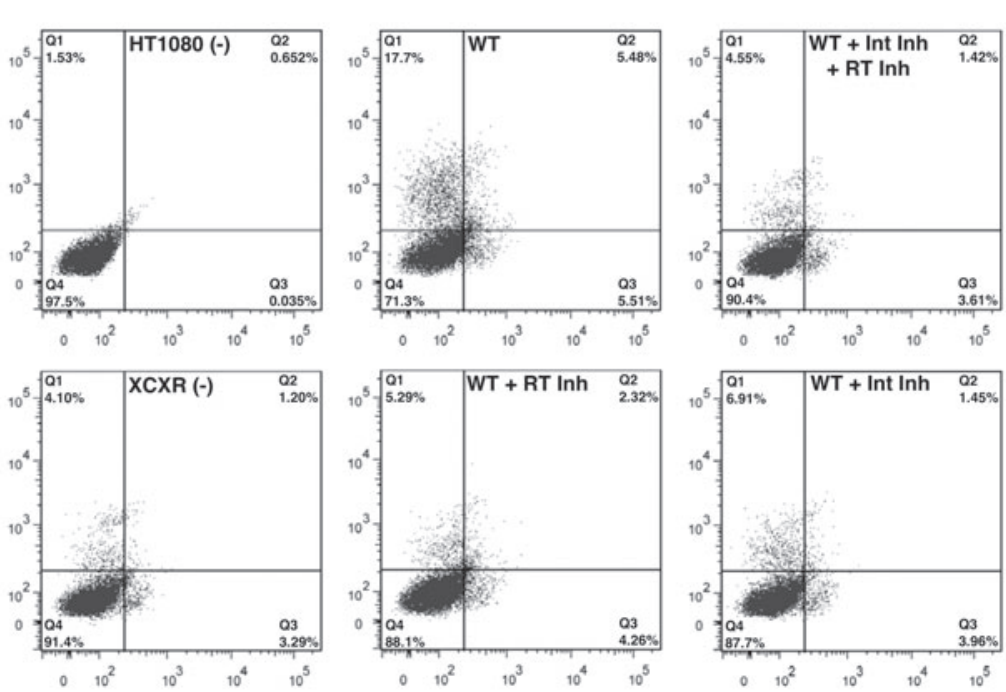
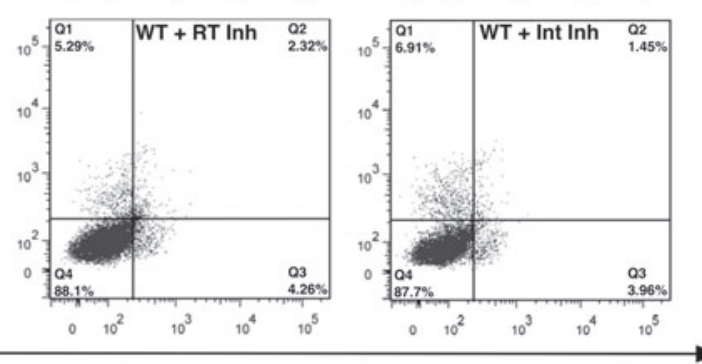

Comp-CFP 


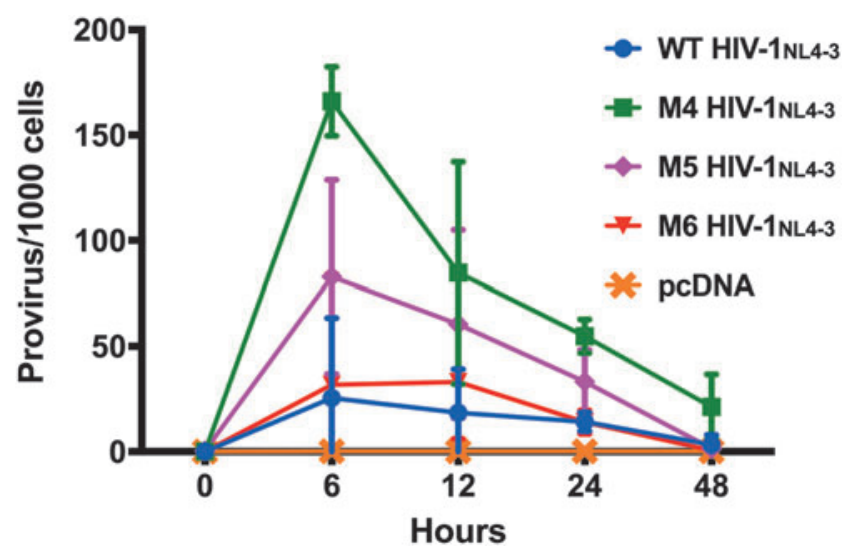

FIG. 7. Rev nucleolar mutations lead to the deregulation of HIV-1 $1_{\mathrm{NL} 4-3}$ integration. Viral supernatant (20 ng p24 capsid) collected during the propagation of WT HIV- $1_{\mathrm{NL} 4-3}$ and HIV $-1_{\mathrm{NL} 4-3}$ variants M4, M5, and M6 was used to infect JLTRG-R5. Genomic DNA was harvested from JLTRG-R5 hosts starting $6,12,24$, and $48 \mathrm{~h}$ postinfection. Genomic DNA was diluted to $2 \mu \mathrm{g} / \mathrm{ml}$ and quantified for integrated viral DNA using a two-step Alu-gag PCR method. Viral integration of HIV $-1_{\mathrm{NL} 4-3}$ variants (M4 and M5) occurred at extremely higher frequency than WT HIV $-1_{\mathrm{NL} 4-3}$ beginning $6 \mathrm{~h}$ after infection. Variant M6 exhibited similar integration copies to that of WT. Integrated copies began to decrease $12 \mathrm{~h}$ postinfection and continued to decrease gradually until the 48-h time point. Supernatant collected from pCDNA during viral propagation was used as a negative control for viral integration.
NoLS M1-RQRQ in our study) from Rev resulted in nucleolar accumulation, previously observed in COS-7 cells. ${ }^{34}$ Removal of amino acids 45-51 (M7-WRERQRQ in our study) caused nuclear dispersion, also previously observed in COS-7.

With and without HIV-1 production, Rev mutations containing two arginine residues within the NoLS motif are exclusively nucleolar in pattern (Rev-NoLS M4, M5, M6, and M8) as WT Rev originally containing three arginine residues within the NoLS motif. We currently demonstrate the dependence of Rev nucleolar accumulation on the presence of at least two arginine residues within Rev-NoLS.

Nucleolar localization of HIV-1 Rev and HTLV-1 Rex was previously demonstrated unnecessary for accumulation of cytoplasmic unspliced RNA when tethered to an RNA operator through MS2 fusion in the absence of viral response elements $^{55}$; nucleolar trafficking was therefore believed to occur through the high affinity of viral proteins with nucleolar constituents that were described as unessential for Rev activity.

We investigated the significance of Rev nucleolar trafficking and localization in HIV production models through the rescue of Rev-deficient HIV- $1_{\mathrm{HXB} 2}$ with Rev-NoLS mutations. In contrast to the previous finding, we revealed that Rev mutations lacking nucleolar entry are nonfunctional in HIV proliferation and viral RNA packaging (M9). Partial nuclear/ nucleolar localization did not rescue viral productivity (M1, M2, and M7).

Mutations M1, M2, and M7 lack two arginine residues within the Rev-NoLS seuqence, and M9 lacks three arginine residues; this would lead to conformational changes within

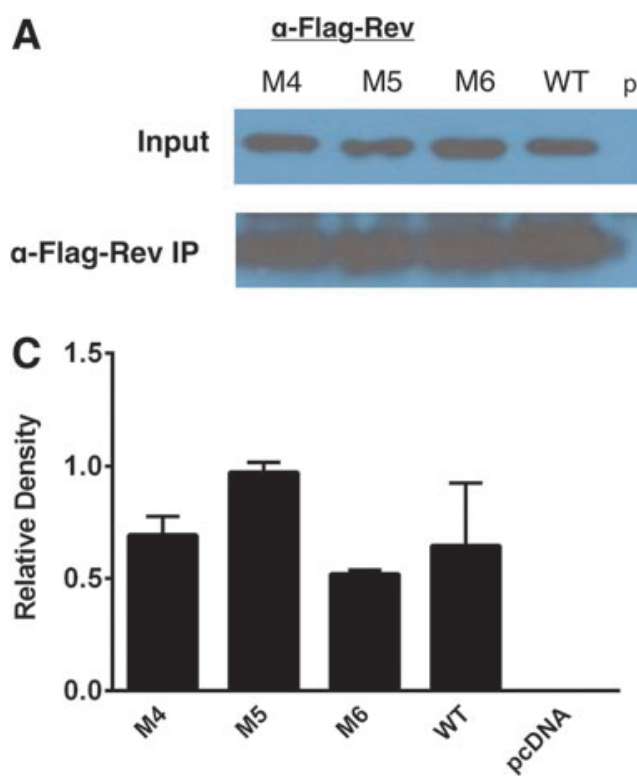

Rev-NoLS Mutations
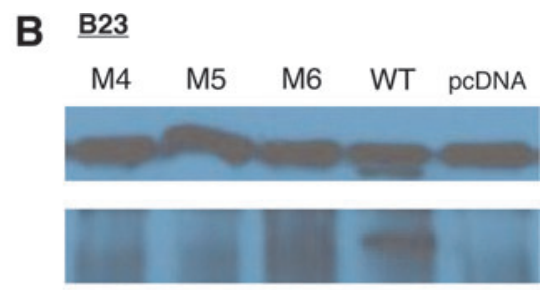

D

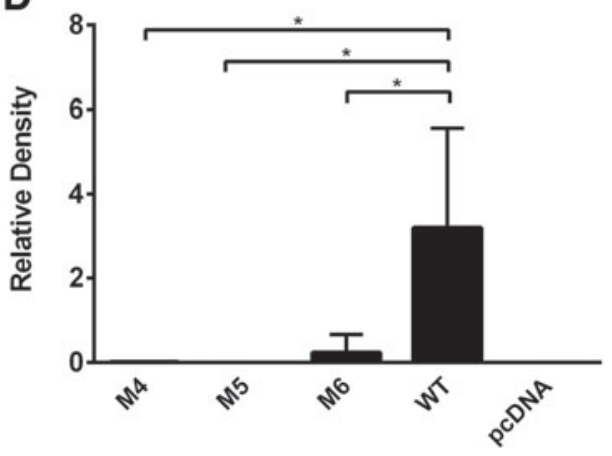

Rev-NoLS Mutations

FIG. 8. Affinity of nucleolar Rev-NoLS mutations to B23 during viral production. HLfB culture was transfected with Rev-NoLS mutations and protein lysate was collected $48 \mathrm{~h}$ after viral proliferation. Lysates were subjected to $\alpha$-Flag-Rev IP and immunodetection against B23, and assessed through Western immunoblotting. (A) Input and IP blots were incubated with $\alpha$-Flag antibody for detection of Rev expression during viral proliferation. Input and IP blots were analyzed for B23 detection and affinity to Rev during viral proliferation (B). Relative density of Rev-NoLS mutations (C) and B23 affinity (D) were analyzed and compared to WT Rev expression and B23 affinity ( $p$ values of M4 =.04, M5=.04, and M6=.05). IP, immunoprecipitation; $* p<.05$. 
the $\alpha$-helical structure of Rev-NoLS and interrupt Rev/RRE binding activity.

The nonfunctional activity of M1, M2, M7, and M9 to rescue viral production could be attributed to the inability of Rev mutations to bind to the RRE of HIV-1 mRNAs. Strictly nucleolar Rev mutations functioned in viral production (M4, M5, and M6), however, with reduced efficiency compared to WT Rev. Nucleolar-localizing M8 contains two missing amino acids from NoLS ( $\mathrm{Arg}^{50}$ and $\mathrm{Gln}^{51}$ ) and resulted in defective viral production. This insufficiency in the rescue of viral production and viral RNA packaging, despite nucleolar accessibility of M8, provides evidence that HIV-1 infection is also dependent on efficient splicing and transport of HIV-1 mRNA - both processes that take place within the nucleolus.

Substitution of arginine residues at the carboxyl terminus of the Rev NLS to alanine ( $\mathrm{Arg}^{46}, \mathrm{Arg}^{48}$, and $\mathrm{Arg}^{50}$ ) was previously demonstrated to reduce Rev/RRE binding threefold. ${ }^{4}$ Our observations yielded similar results upon substitution of these arginine residues to glycine. p24 capsid expression originates from unspliced HIV-1 mRNA transported to the cytosol through Rev/RRE interactions. We observed a decrease in p24 expression in our Rev-deficient $\mathrm{HIV}-1_{\mathrm{HXB} 2}$ model upon viral production with the expression of nucleolar-localizing single-point mutations (Rev-NoLS M4, M5, and M6). In comparison to WT Rev, single-point mutations led to a three-fold decrease in p24 protein as well as decreases in packaged genomic RNA.

Mutation of arginine residues to a similar basic amino acid-lysine-did not affect Rev/RRE binding. ${ }^{4} \mathrm{Arg}^{46}$, $\mathrm{Arg}^{48}$, and $\mathrm{Arg}^{50}$ at the carboxyl terminus of the Rev ARM are moderately important for phosphate and van der Waals interactions between Rev and RRE of the HIV-1 mRNA. ${ }^{5}$ These interactions stabilize the $\alpha$-helical orientation of Rev ARM within the RRE RNA groove. The inability of nucleolar-localizing Rev-NoLS M8 to rescue Rev deficiency during viral production is postulated to result from two missing amino acids from the NoLS motif ( $\mathrm{Arg}^{50}$ and $\left.\mathrm{Gln}^{51}\right)$.

This would lead to the destabilization of the Rev ARM and the RRE. Rev-NoLS M8 deletions would additionally lead to a loss in nucleolar-specific protein interactions with Rev-NoLS. Inability to rescue viral production and genomic RNA packaging despite nucleolar access reveals that Rev nucleolar localization is insufficient for the progression of the HIV-1 infectious cycle. HIV-1 infection may be able to manipulate host cellular pathways at the subnuclear level, and nucleolar access is too simple an explanation for Rev function. Misplaced protein interactions from nucleolar-localizing Rev-NoLS mutations (M4, M5, M6, and M8) in comparison to WT Rev could identify nucleolar pathways required for HIV-1 production.

Viral particles generated in the background of Rev-NoLS single-point mutations are capable of transduction and infection at extremely low frequency. $V S V G$-pseudotyped lentivirus generated with Rev-NoLS mutations replicated, yet lacked transducibility.

Similarly, mutations introduced into the HIV- $1_{\mathrm{NL4}-3} \mathrm{cDNA}$ did not hinder viral production, yet resulted in the inability of HIV-1 variants to infect host cells. We quantified the potency of Rev-NoLS single-point mutations on viral infection through viral output 32 days postinfection. Mutant virus lacked the ability to regain function and participate in the viral infectious cycle. Unlike Rev-NoLS, single-point mutation R55Q acquired within the HIV-1 Tat basic domain- ${ }^{49} \mathrm{RKKRRQRRRAHQ}{ }^{60}$ required for TAR RNA binding, ${ }^{56,57} \mathrm{NLS}^{58}$ and $\mathrm{NoLS}^{59}$ delayed HIV-1 $1_{\mathrm{NL} 4-3}$ production 12 days in comparison to WT Tat. ${ }^{60}$ Other single-point mutations R52Q, R55Q, and R57Q did not significantly affect Tat function in the transactivation of viral genes.

\section{Rev-NoLS in HIV-1 mRNA splicing}

HIV-1 mRNA splicing involves the interplay of core splicing signals, exonic/intronic splicing enhancers and silencers, and the secondary structure of the pre-mRNA. ${ }^{61}$ Core splicing signals are composed of the following three sites commonly found in pre-mRNA: $5^{\prime}$-splice site $\left(5^{\prime} \mathrm{ss}\right) ; 3^{\prime}$-splice site ( $\left.3^{\prime} \mathrm{ss}\right)$; and branch point sequence (BPS). $5^{\prime}$ ss recruits the splicing factor U1 snRNP, and the 3'ss allows interaction with another splicing factor-U2AF. BPS binds to the SF1/mBBP branch point binding protein, later displaced by U2 snRNP during formation of the spliceosomal complex.

5'ss and 3'ss are categorized in pairs throughout mammalian pre-mRNA and are classified as strong or weak splice sites based on affinity with corresponding splicing factors (5'ss with U1 snRNA, or 3'ss with U2AF and SF1/mBBP of the BPS). Exon definition and bridging between 5'ss and 3'ss lead to formation of an early, irreversible splicing complex (E complex), resulting in splicing reactions. ${ }^{62,63}$ Core splicing signals are surrounded by cis-elements that either enhance (exonic splicing enhancers [ESEs]) or repress (exonic splicing silencers [ESSs]) exon definition during alternative splicing reactions. ${ }^{64,65}$

ESEs are sequence elements within exons that interact with serine-arginine-rich splicing factors (SR proteins). ESSs interact with the heterogeneous ribonuclear splicing inhibitors (hnRNP) to repress exon definition. Intronic splicing silencers (ISSs) and intronic splicing enhancers are sequences within introns that facilitate exon definition. The premRNA secondary structure is able to modulate alternative splicing reactions through exposure of core splicing signals and regulatory cis-elements. ${ }^{66}$ Accumulation of partially spliced and unspliced viral mRNA is dependent on the presence of the RRE, located between 5'ss D4 and 3'ss A7 (Supplementary Fig. S7). mRNA encoding Vif, Vpr, and Tat is expressed at extremely low levels, indicating the infrequent activity of 3'ss A1, A2, and A3. ${ }^{67}$

Partially spliced $4 \mathrm{~kb}$ vif mRNA, a product of 5'ss D1 to 3'ss A1, composes $1 \%$ of incompletely spliced viral mRNA in infected cells. $V p r$ mRNA, a product of 5'ss D1 to 3'ss A2, composes $2 \%$ of total partially spliced mRNAs. Approximately half of all spliced viral mRNA is fully spliced $2 \mathrm{~kb}$ mRNA, indicating frequent splicing at 3'ss A7. Tat mRNA composes $9 \%$ of completely spliced mRNA (two-exon Tat) and $5 \%$ of partially spliced mRNA (one-exon Tat). Tat mRNAs are formed through splicing activity at 5'ss of D1, D2, D3, or D4 to 3'ss A3.

Transcripts leading to Vpu, Env, and Rev are abundantly expressed, indicating the frequent use of 3'ss A4c, A4a, A4b, and A5. The center of HIV-1 pre-mRNA contains 3'ss clusters leading to the accumulation of fully spliced rev mRNA (5'ss D3 or D4 to 3'ss of A4c, A4a, or A4b), fully spliced nef mRNA (5'ss D3 or D4 to 3'ss A5), and partially spliced env/ vpu mRNAs (5'ss D2 or D3 to 3'ss cluster). Both populations compose $90 \%$ of completely spliced mRNA and $92 \%$ of partially spliced mRNA. 
Alternatively, mRNA leading to expression of two-exon Tat, Rev, and Nef utilizes 3'ss A7. Efficient splicing activity at A7 requires ESS, ESE, and ISS elements. ${ }^{68,69}$ Novel 5'ss D1A and 3'ss A1A identified within gag/pol mRNA are utilized at low frequency compared to other splice sites within the HIV-1 pre-mRNA. ${ }^{70}$ The $5^{\prime}$ 'ss D1A is suggested as a necessary feature to prevent the degradation of unspliced viral mRNA. U1 snRNP bound to 5'ss D1A recruits SR proteins that may stabilize the binding of Rev to the viral RNA, leading to the nuclear export of unspliced HIV-1 RNA.

Based on the observations of Rev mutations (M4, M5, and M6), the inability of lentivirus to replicate and package mRNA may result from single-point mutational defects affecting Rev/ RRE binding and nucleocytoplasmic transport. Specifically, $\mathrm{Arg}^{35}$ and $\mathrm{Arg}^{39}$ of Rev ARM interact with nucleotides U66, G67, and G70 of RRE major groove; $\mathrm{Asn}^{40}$ and $\mathrm{Arg}^{44}$ interact with U45, G46, G47, and A73, opposite the major groove. ${ }^{4}$ $\mathrm{Arg}^{46}, \mathrm{Arg}^{48}$, and $\mathrm{Arg}^{50}$ at the COOH terminus of Rev ARM are suggested as being moderately important for specific binding to achieve phosphate and van der Waals contacts in an $\alpha$-helical orientation within the RRE groove. ${ }^{5}$

In our studies, substitution of Rev Arg ${ }^{46}$ (M4), $\operatorname{Arg}^{48}$ (M5), and $\mathrm{Arg}^{50}$ (M6) with glycine within proviral cDNA leads to spliceosomal irregularities. The $9 \mathrm{~kb}$ mRNA of HIV-1 $1_{\mathrm{NL} 4-3}$ variants significantly reduced in expression compared to WT HIV-1 ${ }_{\text {NL4-3 }}$; Arg $^{50}-$ Gln $^{51}$ deletion within the M8 variant exhibited abundant 4 and $2 \mathrm{~kb}$ mRNA than WT HIV- $1_{\mathrm{NL} 4-3}$. These findings exemplify the importance of Rev-NoLS in RRE binding and HIV-1 mRNA transport.

We observed that Rev single-point mutations decrease the cytoplasmic export of the $9 \mathrm{~kb}$ HIV-1 mRNA, thereby leading to the decrease of p24 production, since p24 is derived from gag/pol precursors of $9 \mathrm{~kb}$ mRNA. ${ }^{46,71}$ Two amino acid deletions of M8 did not significantly change the levels of the $9 \mathrm{~kb}$ mRNA, although disproportionately higher levels of 2 and $4 \mathrm{~kb}$ mRNA splice variants were observed. Impairment of Rev in facilitating nucleocytoplasmic transport of unspliced and partially spliced transcripts could result in the accumulation of fully spliced $2 \mathrm{~kb}$ transcripts, which encode Tat, Rev, and Nef proteins. Therefore, an increase of Tat expression would activate the Tat-positive feedback loop, leading to the enhanced transactivation of HIV gene expression and the subsequent accumulation of 2 and $4 \mathrm{~kb}$ mRNAs. ${ }^{6,72}$

This is also consistent with computational models, which predict an increase of 2, 4, and $9 \mathrm{~kb}$ transcripts upon inhibition of Rev. ${ }^{73}$ The proportionality of spliced/unspliced mRNA variants may be a prerequisite for viral production and infection. In addition, host cell protein interactions with Rev in the nucleolus may regulate HIV mRNA transport and splicing.

Nucleolar B23 is involved in nucleocytoplasmic shuttling of Rev-bound HIV mRNA and is well characterized in its interactions with the NoLS of host factors-p120 growth factor (amino acids 40-57) ${ }^{74}$ and C23 pre-rRNA processor (amino acids 540-628) ${ }^{75}$-and retroviral proteins HTLV-1 Rex (amino acids $1-22)^{76}$ and HIV-1 Tat (amino acids 4957). ${ }^{77}$ Currently, we reveal that Rev-NoLS single-point mutations abolished B23 interaction with Rev. This may lead to the disruption of nucleocytoplasmic shuttling of HIV mRNAs. We also reveal that the loss of B23 interaction with Rev does not hinder viral production, yet diminishes viral infectivity, suggesting that other nucleolar factors are involved in viral production.
Rev-NoLS in the viral entry, reverse transcription, and integration of HIV-1

Rev single-point mutations were demonstrated to allow the

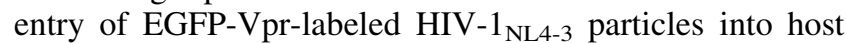
cells. We postulated that defects in HIV-1 production in the presence of nucleolar mutations occur postentry during reverse transcription and/or integration. Rev-NoLS mutants $\mathrm{M} 4_{\mathrm{NL4}-3}, \mathrm{M} 5_{\mathrm{NL} 4-3}$, and M6 $6_{\mathrm{NL4}-3}$ exhibited reduced expression of p24 capsid, RT, and packaged RNA; this would result from the reduced expression of $\mathrm{Gag} / \mathrm{Pol}$ precursors as well as the $\Psi$ packaging element, all originating from $9 \mathrm{~kb} \mathrm{HIV}$ mRNA, in the presence of single-point mutations. Rev mutant $\mathrm{M} 8_{\mathrm{NL} 4-3}$ produced $\mathrm{p} 24$ capsid, RT, and packaged RNA at extremely low quantities in comparison to HIV-1 mutants $\mathrm{M} 4_{\mathrm{NL} 4-3}, \mathrm{M} 5_{\mathrm{NL} 4-3}$, and $\mathrm{M} 6_{\mathrm{NL} 4-3}$; this would result from the constant splicing of the $9 \mathrm{~kb}$ mRNA and accumulation of 4 and $2 \mathrm{~kb}$ mRNA fragments in the presence of nonfunctional Rev M8.

Nullbasic, a transdominant negative mutation of Tat, contains glycine/alanine substitutions of the Tat basic domain (amino acids 49-57). Nullbasic was demonstrated to reduce HIV-1 infection of MAGI, Jurkat, and human primary $\mathrm{CD}^{+} \mathrm{T}$ cells during reverse transcription. ${ }^{78,79}$ The mechanism by which Nullbasic interrupts reverse transcription is unclear. Nullbasic Tat was further demonstrated in redistribution of nucleolar Rev to cytoplasm and downregulation of Rev-mediated mRNA transport and expression of Gag-derived proteins. ${ }^{78}$ Nullbasic co-expression with Rev caused dispersion of nucleolar CRM1, B23, and nucleolin to the nucleus. ${ }^{80}$

Absence of the Tat basic domain in Nullbasic, which interacts with B23, ${ }^{77}$ would suggest alternative indirect interactions between Tat and Rev besides B23. Mutation within Rev-NoLS may in turn interrupt Tat function through this unknown pathway; identification of host factors involved in this mechanism would explain reverse transcription deficiencies in the presence of Nullbasic Tat as well as Rev-NoLS single-point mutations. Alternatively, nucleolar factors such as B23 may be required within viral particles to directly facilitate reverse transcription postentry, and reduction of cellular factors through Rev-NoLS mutations could lead to the defects and reduction of reverse transcription.

Lentivirus generated in the background of Rev-NoLS single-point mutations (M4, M5, and M6) transduced host cells, however, at extremely low frequency in comparison to WT lentivirus. Transducibility in this model is defined by the ability of lentivirus to achieve host cell entry, reverse transcription, and integration. These events are quantifiable through reporters placed within the lentiviral backbone (HIV7/C-GFP contains a $G F P$ reporter to detect reverse transcription and integration; $C V I T G$ contains GFP for detection of reverse transcription and integration, and produces Cre to induce Cre-LoxP-dependent cleavage of stably expressed LoxP-CFP-LoxP-RFP reporters for detection of lentiviral entry in HT1080-XCXR hosts).

The inability of $H I V 7 / C-G F P$ and $C V I T G$ lentivirus to fully transduce host cells in the presence of Rev-NoLS mutations reveals a deficiency during the integration step. In a separate infectious model, deficient integration was observed upon inability of $\mathrm{HIV}-1_{\mathrm{NL} 4-3}$ variants to integrate into JLTRG-R5 hosts, preventing the Tat-inducible activation of internal LTR-EGFP reporters. 
A previous study demonstrated the intracellular interaction of HIV-1 integrase and Rev using bimolecular fluorescence complementation and co-IP assay systems. ${ }^{81} \mathrm{Rev}$ protein is initially transcribed from unintegrated viral DNA at the early stages of infection before the integration step occurs, and is believed to have inhibitory effects on the enzymatic activity of integrase. An HIV-1-infected cell typically contains a limited number of integrated viral genomes per host cell-namely one or two integration events have been observed. Several integration events are documented in other retroviruses-murine leukemia virus and Rous sarcoma virus - suggesting different regulatory mechanisms of viral integration in other retroviral models.

Two integrase-derived peptides ( $\mathrm{INr}-1$ and $\mathrm{INr}-2$ ) were shown to diminish the inhibitory effects of Rev on integrase activity and stimulate multiple viral DNA integration events during kinetics studies. These findings suggest the involvement of the Rev nucleolar pathway in the regulation of lentiviral integration. Formation of the lens epithelium-derived growth factor p75 (LEDGF/p75) complex with Rev was previously observed as a crucial step in regulating viral cDNA integration. ${ }^{82}$ Co-IP experiments revealed that an IN$\mathrm{LEDGF} / \mathrm{p} 75$ complex is formed postinfection, which is later replaced by Rev-LEDGF/p75 and Rev-IN complexes. Nucleolar single-point mutations, namely in the background of M4 and M5, may hinder the Rev-dependent regulation of integrase. This would result in the high frequencies of viral integration observed in this study.

\section{Cellular host factors involved in the HIV-1 nucleolar pathway}

Single-point mutations induced within Rev-NoLS were expected to decrease binding affinity to other cellular host factors facilitating Rev functionality in HIV mRNA binding and transport. Nucleolar B23 is involved in the nucleocytoplasmic shuttling of Rev-bound mRNA. ${ }^{53,54}$ Rev-NoLS single-point mutations in this model abolished B23 affinity to Rev, indicating disruption in nucleocytoplasmic shuttling and HIV mRNA transport. Disruption of B23 interaction with Rev in turn does not hinder viral production, yet diminishes ability to produce infectious viral particles. We postulate that nucleolar factors, transport factors, and splicing factors involved in B23 function further participate in the HIV-1 infectious cycle.

B23-mediated transport of nucleolar viral proteins, viral assembly, encapsidation, production, and latency is documented in other viral infectious models. B23 is characterized in interactions with NoLS of cellular factors for nucleocytoplasmic transport-p120 growth factor (amino acids $40-57)^{74}$ and C23 pre-rRNA processor (amino acids 540$628)^{75}$ - and with retroviral proteins HTLV-1 Rex (amino acids $1-22),{ }^{76}$ HIV-1 Tat (amino acids $\left.49-57\right),{ }^{77}$ and HIV-1 Rev (amino acids 37-47). ${ }^{83}$ Juvenile Encephalitis virus (JEV) infection is transmitted through mosquito vectors, leading to acute encephalitis in humans. The JEV genome encodes a nucleolar-localizing core protein, through which amino acids Gly42 and Pro43 interact with N-terminal region of B23 during JEV infection, resulting in transportation of viral core protein/B23 into the nucleus. ${ }^{84}$

The single-strand RNA HBV causes cirrhosis and hepatocellular carcinoma during infection. The HBV genome is composed partially of double-stranded DNA, which encodes a nucleolar core protein. HBV core protein associates with nucleolin and B23 in the nucleolus ${ }^{85}$; B23 was demonstrated in HBV assembly through interaction with the core protein $\mathrm{N}$ terminal domain. Specifically, B23 amino acids 259-294 bind the N-terminal domain of $\mathrm{HBV}$ core protein to allow viral encapsidation. ${ }^{86}$

The negative-sense, single-strand RNA hepatitis D virus (HDV) expresses HDVAg antigen in two isoforms; the small isoform aids in RNA replication and the large isoform facilitates viral assembly. RNA replication takes place within the nucleolus and requires B23 interaction with HDVAg. ${ }^{87,88}$ HDV infection causes an upregulation of B23, which interacts mostly with the small HDVAg isoform and less with the large HDVAg isoform. Interactions take place through the small HDVAg NLS domain, through which B23 binds and achieves nuclear accumulation. Upon deletion of HDV binding site to B23, RNA replication was impaired. HDVAg was shown to co-localize with B23 and nucleolin in the nucleolus. Nucleolin was discovered to possess transcriptional properties as a repressor, ${ }^{89}$ revealing the nucleolus as a compartment for regulation of HDV replication.

B23 is involved in latency of the double-strand DNA Kaposi sarcoma herpesvirus (KSHV), which leads to Kaposi's sarcoma and is associated with AIDS-induced nonHodgkin lymphoma. KSHV latent protein-V-cyclin-with host CDK6 kinase phosphorylates B23 at Thr199, facilitating B23 interaction with latency-associated nuclear antigen. ${ }^{90}$ The latency-associated nuclear antigen acts to prevent viral lytic replication. Depletion of B23 leads to KSHV reactivation, revealing $\mathrm{B} 23$ as a regulator of $\mathrm{KSHV}$ latency. B23 function in the HIV production cycle is characterized in nucleocytoplasmic transport activity of Tat and Rev, and it is unknown if B23 can induce latency during HIV infection. B23 involvement in the production, encapsidation, and assembly of HIV is also unknown.

\section{Conclusion}

We currently demonstrate Rev nucleolar access a requirement for HIV-1 production and pathogenesis. This localization pattern allows efficient HIV-1 mRNA splicing and nucleocytoplasmic transport. We reveal an extra step during the HIV-1 infectious cycle in the nucleolus through Rev nucleocytoplasmic activity, required for production of infectious viral particles. Interference with nucleolar activity through mutation of Rev-NoLS diminishes the ability of HIV-1 to regulate viral integration within host cells, thereby leading to host cell death and termination of the viral infectious cycle.

In summary, we find that HIV-1 utilizes a nucleolar pathway to maintain an infectious cycle. Our findings suggest that this understudied pathway is a novel therapeutic target for the interference of HIV-1 infection. Nucleolar manipulation could be applicable against other viral infections and disease models requiring nucleolar access.

\section{Acknowledgments}

We acknowledge Dr. Barbara K. Felber and Dr. George N. Pavlakis for HLfB adherent culture and Dr. Olaf Kutsch for JLTRG-R5 suspension cells, provided by the NIH AIDS Research and Reference Reagent Program, Division of 
AIDS, NIAID, NIH. We kindly thank Dr. Ulrike Jung for pNL4-3 cloning expertise, and Dr. John Zaia for support. We finally acknowledge financial sources provided by the $\mathrm{Na}$ tional Institutes of Health, Grants AI042552 and AI029329.

\section{Authors' Contributions}

J.A.C.A. generated all Rev-NoLS mutations and HIV$1_{\mathrm{NL} 4-3}$ variants, created Nef probe for Northern blotting, and carried out all experiments discussed throughout the article. M.T. contributed Alu-gag qPCR experiments for detection of integrated HIV-1 DNA. J.C.B. created the dual Cre-LoxP lentiviral reporter and CVITG backbone, participated in designing the dual reporter study, and helped to draft the Results section of the article. D.L.O. conducted the co-localization of Rev-NoLS mutations with B23 in HeLa (absence of HIV-1 production) and generated the Flag-WT Rev fusion, later used as a template for Rev-NoLS-3'Flag mutagenesis. J.J.R. proofread and edited the final article.

\section{Author Disclosure Statement}

No competing financial interests exist.

\section{References}

1. Hauber J, Perkins A, Heimer EP, Cullen BR: Trans-activation of human immunodeficiency virus gene expression is mediated by nuclear events. Proc Natl Acad Sci U S A 1987;84: 6364-6368.

2. Ruben S, Perkins A, Purcell R, et al:: Structural and functional characterization of human immunodeficiency virus tat protein. J Virol 1989;63:1-8.

3. Berkhout B, Silverman RH, Jeang KT: Tat trans-activates the human immunodeficiency virus through a nascent RNA target. Cell 1989;59:273-282.

4. Battiste JL, Mao H, Rao NS, et al.: Alpha helix-RNA major groove recognition in an HIV-1 rev peptide-RRE RNA complex. Science 1996;273:1547-1551.

5. Tan R, Chen L, Buettner JA, Hudson D, Frankel AD: RNA recognition by an isolated alpha helix. Cell 1993;73: 1031-1040.

6. Malim MH, Hauber J, Le SY, Maizel JV, Cullen BR: The HIV-1 rev trans-activator acts through a structured target sequence to activate nuclear export of unspliced viral mRNA. Nature 1989;338:254-257.

7. Heaphy S, Dingwall C, Ernberg I, et al.: HIV-1 regulator of virion expression (Rev) protein binds to an RNA stem-loop structure located within the Rev response element region. Cell 1990;60:685-693.

8. Fang X, Wang J, O'Carroll IP, et al.: An unusual topological structure of the HIV-1 Rev response element. Cell 2013; 155:594-605.

9. Iwai S, Pritchard C, Mann DA, Karn J, Gait MJ: Recognition of the high affinity binding site in rev-response element RNA by the human immunodeficiency virus type-1 rev protein. Nucleic Acids Res 1992;20:6465-6472.

10. Tiley LS, Malim MH, Tewary HK, Stockley PG, Cullen BR: Identification of a high-affinity RNA-binding site for the human immunodeficiency virus type 1 Rev protein. Proc Natl Acad Sci U S A 1992;89:758-762.

11. Kjems J, Brown M, Chang DD, Sharp PA: Structural analysis of the interaction between the human immunodeficiency virus Rev protein and the Rev response element. Proc Natl Acad Sci U S A 1991;88:683-687.
12. Daugherty MD, Liu B, Frankel AD: Structural basis for cooperative RNA binding and export complex assembly by HIV Rev. Nat Struct Mol Biol 2010;17:1337-1342.

13. Vercruysse T, Pardon E, Vanstreels E, Steyaert J, Daelemans D: An intrabody based on a llama single-domain antibody targeting the N-terminal alpha-helical multimerization domain of HIV-1 rev prevents viral production. J Biol Chem 2010;285:21768-21780.

14. Pond SJ, Ridgeway WK, Robertson R, Wang J, Millar DP: HIV-1 Rev protein assembles on viral RNA one molecule at a time. Proc Natl Acad Sci U S A 2009;106:1404-1408.

15. Daelemans D, Costes SV, Cho EH, Erwin-Cohen RA, Lockett S, Pavlakis GN: In vivo HIV-1 Rev multimerization in the nucleolus and cytoplasm identified by fluorescence resonance energy transfer. J Biol Chem 2004; 279:50167-50175.

16. Fischer U, Huber J, Boelens WC, Mattaj IW, Luhrmann R: The HIV-1 Rev activation domain is a nuclear export signal that accesses an export pathway used by specific cellular RNAs. Cell 1995;82:475-483.

17. Fukuda M, Asano S, Nakamura T, et al.: CRM1 is responsible for intracellular transport mediated by the nuclear export signal. Nature 1997;390:308-311.

18. Daelemans D, Costes SV, Lockett S, Pavlakis GN: Kinetic and molecular analysis of nuclear export factor CRM1 association with its cargo in vivo. Mol Cell Biol 2005;25:728-739.

19. Kim SY, Byrn R, Groopman J, Baltimore D: Temporal aspects of DNA and RNA synthesis during human immunodeficiency virus infection: Evidence for differential gene expression. J Virol 1989;63:3708-3713.

20. Klotman ME, Kim S, Buchbinder A, DeRossi A, Baltimore D, Wong-Staal F: Kinetics of expression of multiply spliced RNA in early human immunodeficiency virus type 1 infection of lymphocytes and monocytes. Proc Natl Acad Sci U S A 1991;88:5011-5015.

21. Canto-Nogues C, Hockley D, Grief C, et al.: Ultrastructural localization of the RNA of immunodeficiency viruses using electron microscopy in situ hybridization and in vitroinfected lymphocytes. Micron 2001;32:579-589.

22. Michienzi A, Cagnon L, Bahner I, Rossi JJ: Ribozymemediated inhibition of HIV 1 suggests nucleolar trafficking of HIV-1 RNA. Proc Natl Acad Sci U S A 2000;97: 8955-8960.

23. Unwalla HJ, Li H, Li SY, Abad D, Rossi JJ: Use of a U16 snoRNA-containing ribozyme library to identify ribozyme targets in HIV-1. Mol Ther 2008;16:1113-1119.

24. Thiry M, Lafontaine DL: Birth of a nucleolus: The evolution of nucleolar compartments. Trends Cell Biol 2005;15: 194-199.

25. Boisvert FM, van Koningsbruggen S, Navascues J, Lamond AI: The multifunctional nucleolus. Nat Rev Mol Cell Biol 2007;8:574-585.

26. Sirri V, Urcuqui-Inchima S, Roussel P, Hernandez-Verdun D: Nucleolus: The fascinating nuclear body. Histochem Cell Biol 2008;129:13-31.

27. Hiscox JA, Whitehouse A, Matthews DA: Nucleolar proteomics and viral infection. Proteomics 2010;10:4077-4086.

28. Timani KA, Liao Q, Ye L, et al.: Nuclear/nucleolar localization properties of C-terminal nucleocapsid protein of SARS coronavirus. Virus Res 2005;114:23-34.

29. Wang SH, Syu WJ, Huang KJ, et al.: Intracellular localization and determination of a nuclear localization signal of the core protein of dengue virus. J Gen Virol 2002;83 (Pt 12):3093-3102. 
30. Rikkonen M, Peranen J, Kaariainen L: Nuclear and nucleolar targeting signals of Semliki Forest virus nonstructural protein nsP2. Virology 1992;189:462-473.

31. Kjems J, Sharp PA: The basic domain of Rev from human immunodeficiency virus type 1 specifically blocks the entry of U4/U6.U5 small nuclear ribonucleoprotein in spliceosome assembly. J Virol 1993;67:4769-4776.

32. Dundr M, Leno GH, Hammarskjold ML, Rekosh D, HelgaMaria C, Olson MO: The roles of nucleolar structure and function in the subcellular location of the HIV-1 Rev protein. J Cell Sci 1995;108(Pt 8):2811-2823.

33. Kubota S, Siomi H, Satoh T, Endo S, Maki M, Hatanaka M: Functional similarity of HIV-I rev and HTLV-I rex proteins: Identification of a new nucleolar-targeting signal in rev protein. Biochem Biophys Res Commun 1989;162: 963-970.

34. Cochrane AW, Perkins A, Rosen CA: Identification of sequences important in the nucleolar localization of human immunodeficiency virus Rev: Relevance of nucleolar localization to function. J Virol 1990;64:881-885.

35. Perkins A, Cochrane AW, Ruben SM, Rosen CA: Structural and functional characterization of the human immunodeficiency virus rev protein. J Acquir Immune Defic Syndr 1989;2:256-263.

36. Lee NS, Dohjima T, Bauer G, et al.: Expression of small interfering RNAs targeted against HIV-1 rev transcripts in human cells. Nat Biotechnol 2002;20:500-505.

37. Brussel A, Sonigo P: Analysis of early human immunodeficiency virus type 1 DNA synthesis by use of a new sensitive assay for quantifying integrated provirus. J Virol 2003;77:10119-10124.

38. Yam PY, Li S, Wu J, Hu J, Zaia JA, Yee JK: Design of HIV vectors for efficient gene delivery into human hematopoietic cells. Mol Ther 2002;5:479-484.

39. Li M, Rossi JJ: Lentiviral vector delivery of siRNA and shRNA encoding genes into cultured and primary hematopoietic cells. Methods Mol Biol 2008;433:287-299.

40. Bagasra O, Khalili K, Seshamma T, Taylor JP, Pomerantz RJ: TAR-independent replication of human immunodeficiency virus type 1 in glial cells. J Virol 1992;66:75227528.

41. Eriksson S, Graf EH, Dahl V, et al.: Comparative analysis of measures of viral reservoirs in HIV-1 eradication studies. PLoS Pathog 2013;9:e1003174.

42. Graf EH, Mexas AM, Yu JJ, et al.: Elite suppressors harbor low levels of integrated HIV DNA and high levels of 2LTR circular HIV DNA compared to HIV+ patients on and off HAART. PLoS Pathog 2011;7:e1001300.

43. Liszewski MK, Yu JJ, O'Doherty U: Detecting HIV-1 integration by repetitive-sampling Alu-gag PCR. Methods 2009;47:254-260.

44. O'Doherty U, Swiggard WJ, Jeyakumar D, McGain D, Malim MH: A sensitive, quantitative assay for human immunodeficiency virus type 1 integration. J Virol 2002;76: 10942-10950.

45. Yu JJ, Wu TL, Liszewski MK, et al.: A more precise HIV integration assay designed to detect small differences finds lower levels of integrated DNA in HAART treated patients. Virology 2008;379:78-86.

46. Hadzopoulou-Cladaras M, Felber BK, Cladaras C, Athanassopoulos A, Tse A, Pavlakis GN: The rev (trs/art) protein of human immunodeficiency virus type 1 affects viral mRNA and protein expression via a cis-acting sequence in the env region. J Virol 1989;63:1265-1274.
47. Ochsenbauer-Jambor C, Jones J, Heil M, Zammit KP, Kutsch O: T-cell line for HIV drug screening using EGFP as a quantitative marker of HIV-1 replication. Biotechniques 2006;40:91-100.

48. Kutsch O, Levy DN, Bates PJ, et al.: Bis-anthracycline antibiotics inhibit human immunodeficiency virus type 1 transcription. Antimicrob Agents Chemother 2004;48: 1652-1663.

49. Gu S, Ji J, Kim JD, Yee JK, Rossi JJ: Inhibition of infectious human immunodeficiency virus type 1 virions via lentiviral vector encoded short antisense RNAs. Oligonucleotides 2006;16:287-295.

50. Cullen BR: Nuclear mRNA export: Insights from virology. Trends Biochem Sci 2003;28:419-424.

51. Stauber RH, Rulong S, Palm G, Tarasova NI: Direct visualization of HIV-1 entry: Mechanisms and role of cell surface receptors. Biochem Biophys Res Commun 1999; 258:695-702.

52. Schaeffer E, Geleziunas R, Greene WC: Human immunodeficiency virus type 1 Nef functions at the level of virus entry by enhancing cytoplasmic delivery of virions. J Virol 2001;75:2993-3000.

53. Szebeni A, Mehrotra B, Baumann A, Adam SA, Wingfield PT, Olson MO: Nucleolar protein B23 stimulates nuclear import of the HIV-1 Rev protein and NLS-conjugated albumin. Biochemistry 1997;36:3941-3949.

54. Fankhauser C, Izaurralde E, Adachi Y, Wingfield P, Laemmli UK: Specific complex of human immunodeficiency virus type 1 rev and nucleolar B23 proteins: Dissociation by the Rev response element. Mol Cell Biol 1991;11:2567-2575.

55. McDonald D, Hope TJ, Parslow TG: Posttranscriptional regulation by the human immunodeficiency virus type 1 Rev and human T-cell leukemia virus type I Rex proteins through a heterologous RNA binding site. J Virol 1992;66: 7232-7238.

56. Calnan BJ, Biancalana S, Hudson D, Frankel AD: Analysis of arginine-rich peptides from the HIV Tat protein reveals unusual features of RNA-protein recognition. Genes Dev 1991;5:201-210.

57. Weeks KM, Ampe C, Schultz SC, Steitz TA, Crothers DM: Fragments of the HIV-1 Tat protein specifically bind TAR RNA. Science 1990;249:1281-1285.

58. Efthymiadis A, Briggs LJ, Jans DA: The HIV-1 Tat nuclear localization sequence confers novel nuclear import properties. J Biol Chem 1998;273:1623-1628.

59. Siomi H, Shida H, Maki M, Hatanaka M: Effects of a highly basic region of human immunodeficiency virus Tat protein on nucleolar localization. J Virol 1990;64: 1803-1807.

60. Neuveut C, Jeang KT: Recombinant human immunodeficiency virus type 1 genomes with tat unconstrained by overlapping reading frames reveal residues in Tat important for replication in tissue culture. J Virol 1996;70: 5572-5581.

61. Stoltzfus CM: Chapter 1. Regulation of HIV-1 alternative RNA splicing and its role in virus replication. Adv Virus Res 2009;74:1-40.

62. Hoffman BE, Grabowski PJ: U1 snRNP targets an essential splicing factor, U2AF65, to the $3^{\prime}$ splice site by a network of interactions spanning the exon. Genes Dev 1992;6: 2554-2568.

63. Robberson BL, Cote GJ, Berget SM: Exon definition may facilitate splice site selection in RNAs with multiple exons. Mol Cell Biol 1990;10:84-94. 
64. Matlin AJ, Clark F, Smith CW: Understanding alternative splicing: Towards a cellular code. Nat Rev Mol Cell Biol 2005;6:386-398.

65. Wang Z, Burge CB: Splicing regulation: From a parts list of regulatory elements to an integrated splicing code. RNA 2008;14:802-813.

66. Buratti E, Baralle FE: Influence of RNA secondary structure on the pre-mRNA splicing process. Mol Cell Biol 2004;24:10505-10514.

67. Purcell DF, Martin MA: Alternative splicing of human immunodeficiency virus type 1 mRNA modulates viral protein expression, replication, and infectivity. J Virol 1993; 67:6365-6378.

68. Staffa A, Cochrane A: Identification of positive and negative splicing regulatory elements within the terminal tat-rev exon of human immunodeficiency virus type 1. Mol Cell Biol 1995;15:4597-4605.

69. Amendt BA, Si ZH, Stoltzfus CM: Presence of exon splicing silencers within human immunodeficiency virus type 1 tat exon 2 and tat-rev exon 3: Evidence for inhibition mediated by cellular factors. Mol Cell Biol 1995;15:46064615.

70. Lutzelberger M, Reinert LS, Das AT, Berkhout B, Kjems J: A novel splice donor site in the gag-pol gene is required for HIV-1 RNA stability. J Biol Chem 2006;281:18644-18651.

71. Felber BK, Hadzopoulou-Cladaras M, Cladaras C, Copeland T, Pavlakis GN. Rev protein of human immunodeficiency virus type 1 affects the stability and transport of the viral mRNA. Proc Natl Acad Sci U S A 1989;86: 1495-1499.

72. Malim MH, Hauber J, Fenrick R, Cullen BR: Immunodeficiency virus rev trans-activator modulates the expression of the viral regulatory genes. Nature 1988;335:181-183.

73. Kim H, Yin J: In silico mutagenesis of RNA splicing in HIV-1. Biotechnol Bioeng 2005;91:877-893.

74. Valdez BC, Perlaky L, Henning D, Saijo Y, Chan PK, Busch H: Identification of the nuclear and nucleolar localization signals of the protein p120. Interaction with translocation protein B23. J Biol Chem 1994;269:2377623783.

75. Li YP, Busch RK, Valdez BC, Busch H: C23 interacts with B23, a putative nucleolar-localization-signal-binding protein. Eur J Biochem 1996;237:153-158.

76. Adachi Y, Copeland TD, Hatanaka M, Oroszlan S: Nucleolar targeting signal of Rex protein of human T-cell leukemia virus type I specifically binds to nucleolar shuttle protein B-23. J Biol Chem 1993;268:13930-13934.

77. Li YP: Protein B23 is an important human factor for the nucleolar localization of the human immunodeficiency virus protein Tat. J Virol 1997;71:4098-4102.

78. Meredith LW, Sivakumaran H, Major L, Suhrbier A, Harrich D: Potent inhibition of HIV-1 replication by a Tat mutant. PLoS One 2009; 4:e7769.
79. Apolloni A, Lin MH, Sivakumaran H, Li D, Kershaw MH, Harrich D: A mutant Tat protein provides strong protection from HIV-1 infection in human CD4+ T cells. Hum Gene Ther 2013;24:270-282.

80. Lin MH, Sivakumaran H, Apolloni A, Wei T, Jans DA, Harrich D: Nullbasic, a potent anti-HIV tat mutant, induces CRM1-dependent disruption of HIV rev trafficking. PLoS One 2012;7:e51466.

81. Levin A, Hayouka Z, Helfer M, Brack-Werner R, Friedler A, Loyter A: Peptides derived from HIV-1 integrase that bind Rev stimulate viral genome integration. PLoS One 2009;4:e4155.

82. Levin A, Rosenbluh J, Hayouka Z, Friedler A, Loyter A: Integration of HIV-1 DNA is regulated by interplay between viral rev and cellular LEDGF/p75 proteins. Mol Med 2010;16:34-44.

83. Szebeni A, Herrera JE, Olson MO: Interaction of nucleolar protein B23 with peptides related to nuclear localization signals. Biochemistry 1995;34:8037-8042.

84. Tsuda Y, Mori Y, Abe T, et al.: Nucleolar protein B23 interacts with Japanese encephalitis virus core protein and participates in viral replication. Microbiol Immunol 2006; 50:225-234.

85. Ning B, Shih C: Nucleolar localization of human hepatitis B virus capsid protein. J Virol 2004;78:13653-13668.

86. Lee SJ, Shim HY, Hsieh A, Min JY, Jung G: Hepatitis B virus core interacts with the host cell nucleolar protein, nucleophosmin 1. J Microbiol 2009;47:746-752.

87. Huang WH, Yung BY, Syu WJ, Lee YH: The nucleolar phosphoprotein B23 interacts with hepatitis delta antigens and modulates the hepatitis delta virus RNA replication. J Biol Chem 2001;276:25166-25175.

88. Li YJ, Macnaughton T, Gao L, Lai MM. RNA-templated replication of hepatitis delta virus: Genomic and antigenomic RNAs associate with different nuclear bodies. J Virol 2006;80:6478-6486.

89. Yang TH, Tsai WH, Lee YM, et al.: Purification and characterization of nucleolin and its identification as a transcription repressor. Mol Cell Biol 1994;14:6068-6074.

90. Sarek G, Jarviluoma A, Moore HM, et al.: Nucleophosmin phosphorylation by v-cyclin-CDK6 controls KSHV latency. PLoS Pathog 2010;6:e1000818.

91. Lee N, Rossi JJ: Control of HIV-1 Replication by RNA Interference. Virus Res 2004;102:53-58.

Address correspondence to:

John J. Rossi

Department of Molecular and Cellular Biology Beckman Research Institute at the City of Hope 1500 East Duarte Road Duarte, CA 91010

E-mail: jrossi@coh.org 